\title{
Direct assimilation of Chinese FY-3C Microwave Temperature Sounder-2 radiances in the global GRAPES system
}

\author{
Juan $\mathbf{L i}^{1,2}$ and Guiqing Liu ${ }^{1,2}$ \\ ${ }^{1}$ National Meteorological Center, China Meteorological Administration, Beijing, 100081, China \\ ${ }^{2}$ Numerical Weather Prediction Center, China Meteorological Administration, Beijing, 100081, China \\ Correspondence to: Juan Li (lijuan@pku.org.cn)
}

Received: 23 November 2015 - Published in Atmos. Meas. Tech. Discuss.: 21 January 2016

Revised: 14 May 2016 - Accepted: 6 June 2016 - Published: 19 July 2016

\begin{abstract}
FengYun-3C (FY-3C) is an operational polarorbiting satellite carrying the new-generation microwave sounding instruments in China. This paper describes the assimilation of the FY-3C Microwave Temperature Sounder-2 (MWTS-2) radiances in the Global and Regional Assimilation and PrEdiction System (GRAPES) of China Meteorological Administration. A quality control (QC) procedure for the assimilation of MWTS- 2 radiance is proposed. Extensive monitoring before assimilation shows that MWTS-2 observations exhibit a clear striping pattern. A technique combining principal component analysis (PCA) and ensemble empirical mode decomposition (EEMD) is applied to the observations to remove the striping noise. Cloudy field-of-views (FOVs) are identified by applying the Visible and InfrarRed Radiometer (VIRR) cloud fraction threshold of $76 \%$. Other QC steps are conducted in the follow order: (i) coastal FOVs are removed, (ii) eight outmost FOVs are not used, (iii) channel 5 data over sea ice and land are not used, (iv) channel 6 observations are not used if the terrain altitudes are higher than $500 \mathrm{~m}$, and (v) outliers with large differences between observations and model simulations are removed. Approximately 83, 75, 40, and $40 \%$ of the observations are removed by the proposed QC for channels 5-8, respectively. After QC, the global biases and standard deviations are reduced significantly. The assimilation of the MWTS-2 radiances shows a positive impact when the control experiment assimilates only conventional observations. The experiments also show that the analysis and forecast errors are slightly reduced when the striping noise is removed from the observations. The quality control scheme of extracting the striping noise may contribute to the analysis and forecast accuracy.
\end{abstract}

The impact of MWTS-2 is neutral when the conventional data and other satellite data are all assimilated.

\section{Introduction}

Satellite radiance data have become a critical component in the numerical weather prediction (NWP) system. It is widely accepted that direct assimilation of observations from microwave temperature sounding channels can significantly improve the accuracy of global and regional weather analysis and forecasts (Andersson et al., 1994; Courtier et al., 1998; Derber and Wu, 1998; McNally et al., 2000; Okamoto et al., 2005). Most NWP centers, which made effective early use of ATOVS (Advanced TIROS (Television and Infrared Observational Satellite) Operational Vertical Sounder), onboard NOAA (National Oceanic and Atmospheric Administration)-15/16/17/18/19, MetOp (The Meteorological Operational satellite A)-A/B and Aqua, have reported a substantial reduction in the forecast root mean square (RMS) error. Adjoint-based estimates of observation impact on NWP (Baker and Daley, 2000) have further demonstrated that the greatest decrease in forecast error is due to Advanced Microwave Sounding Unit-A (AMSU-A), which was launched as part of ATOVS and is used primarily for global atmospheric temperature sounding (Fourrié et al., 2002; Langland and Baker, 2004; Cardinali, 2009; Gelaro et al., 2010). Observations from Microwave Temperature Sounder-1 (MWTS-1) onboard Fengyun-3A (FY-3A) and Fengyun-3B (FY-3B) have positive impacts on NWP forecasts ( $\mathrm{Lu}$ et al., 2010; $\mathrm{Lu}$ and Bell, 2012; Li and Zou, 2013, 2014; Li and Liu, 2015). 
On September 23, 2013, the Fengyun-3C (FY-3C) satellite was launched successfully with 11 more advanced instruments on board. It is an operational polar-orbiting environmental research satellite. FY-3C has an afternoon configuration with a local equator crossing time (ECT) of approximately 10 AM. Of particular interest for NWP data assimilation are the Microwave Temperature Sounder-2 (MWTS-2) and the Microwave Humidity Sounder-2 (MWHS-2). After the intensive calibration/validation period in its first 6 months in orbit, the performance of atmospheric sounding instruments in particular meets or exceeds the specifications $(\mathrm{Gu}$ et al., 2013; Guo et al., 2015). An evaluation of FY-3C satellite data quality has been done by Lu et al. (2015). In this article, the assimilation of MWTS-2 will be introduced.

MWTS-2 is more advanced than MWTS- 1 onboard FY3A/B (Dong et al., 2009; Zhang et al., 2009). It has more channels, as shown in Table 1, and samples 90 times rather than 15 in each scan line. Compared with AMSU-A, MWTS2 has one more channel at approximately $50-60 \mathrm{GHz}$. Compared with the Advanced Technology Microwave Sounder (ATMS) onboard the Suomi National Polar-orbiting Partnership (SNPP), the channel specifications of MWTS-2 onboard FY-3C are similar in the $50-60 \mathrm{GHz}$ oxygen line. In addition, FY-3C is a morning satellite and SNNP is an afternoon satellite. The MWTS-2 observations can be complementary to ATMS observations. However, it should also be noticed that compared with ATMS, MWTS-2 contains only the $50 \mathrm{GHz}$ frequencies and thus the other frequencies cannot be used for quality control. In addition, MWTS- 2 does not have the three channels, 23.8, 31.4 and $89 \mathrm{GHz}$ which are often used for cloud detection (Weng and Grody, 1994; Grody et al., 2001; Klaes and Schraidt, 1999). It will make us difficult to detect cloud and precipitation. In all, the FY-3C will contribute to the Global Environmental Observing System of Systems (GEOSS). It is anticipated that the MWTS-2 data could also be useful for NWP modelling systems.

The aim of this study is to assimilate, for the first time, FY3C MWTS-2 radiance data into the Global and Regional Assimilation and PrEdiction System (GRAPES) of China Meteorological Administration (CMA) (Chen et al., 2008; Xue and Chen, 2008, Xue et al., 2008). In this research, the observation processing and quality control (QC) for FY-3C radiance will be developed. The impact of FY-3C MWTS-2 on the GRAPES assimilation system will be evaluated.

This paper is organized as follows. Section 2 describes the general details of the FY-3C MWTS-2 radiance data. Section 3 describes the GRAPES three-dimensional variational assimilation (3D-Var) system. Section 4 provides a quality control scheme of the FY-3C MWTS-2 radiance data. The assessments of MWTS-2 are also provided in this section. Section 5 introduces the bias correction, the setup of the assimilation experiments, and the results of the FY-3C MWTS2 radiance assimilation experiments. A summary and discussion is presented in Sect. 6 .

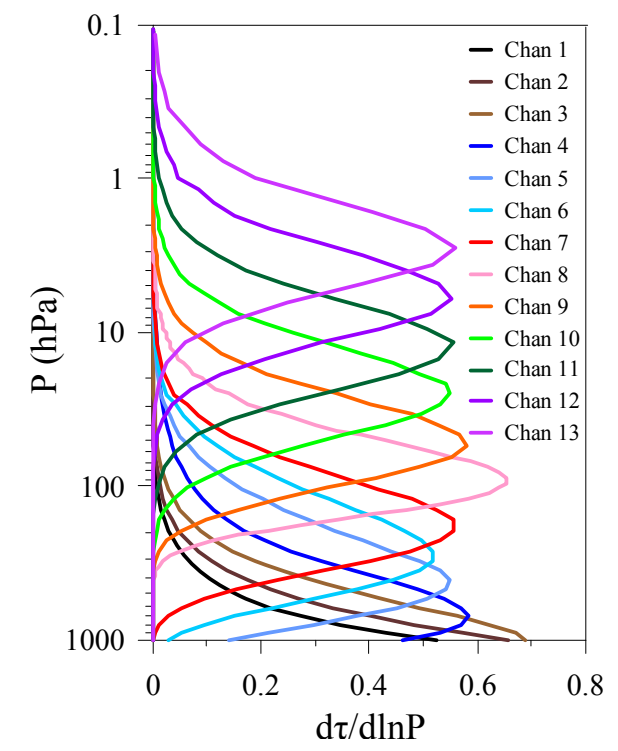

Figure 1. Weighting functions of FY-3C MWTS-2 calculated using US standard atmosphere profile.

\section{FY-3C MWTS-2 observations}

Radiance data in level $1 \mathrm{~b}$ format from the FY-3C MWTS2 are employed for this study for the month of July 2014. Channel characteristics of MWTS-2 are displayed in Table 1 , including the channel frequency, peak weighting function height, and radiometric temperature sensitivity (noise equivalent differential temperature (NEDT)). The NEDTs are about $0.2-0.3 \mathrm{~K}$ for channels $1-7$ and $0.5 \mathrm{~K}$ for channels 9-13. Overall, the observation errors of the mid-upper troposphere sounding channels are smaller than those of the other channels. There are 90 scene FOVs along each MWTS2 scan line. The swath width is $2250 \mathrm{~km}$, and the horizontal FOV resolution at nadir is $32 \mathrm{~km}$.

Figure 1 displays weighting functions calculated from a standard U.S. atmospheric profile for all channels of MWTS2. The absorption and emission of microwave radiation by atmospheric oxygen enables MWTS-2 to passively sound temperature through the atmosphere as a function of altitude. The MWTS-2 has 13 channels in the oxygen band at frequencies between 50.3 and $57.3 \mathrm{GHz}$. It can provide atmosphere temperature information from the Earth's surface to $1 \mathrm{hPa}$ above.

\section{GRAPES 3D-Var system}

GRAPES is the Chinese new global NWP system. The main components of GRAPES include: variational data assimilation (GRAPES 3D-Var); full compressible nonhydrostatic model core with semi-implicit and semi-Lagrangian discretization scheme; modularized model physics pack- 
(a)

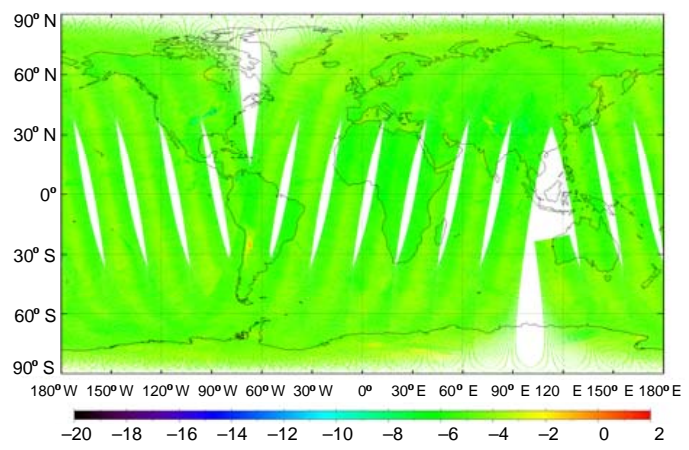

(c)

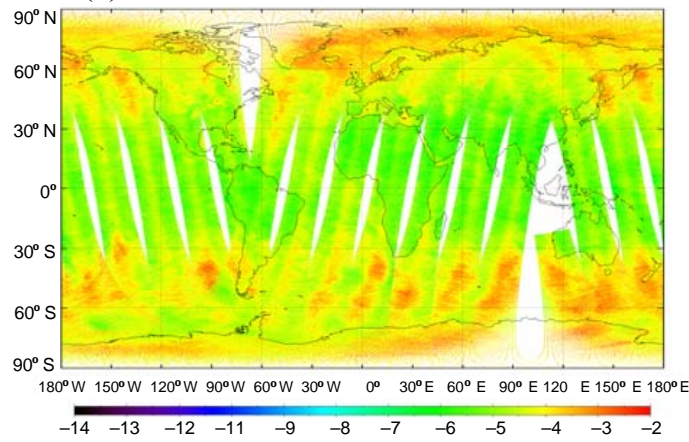

(b)

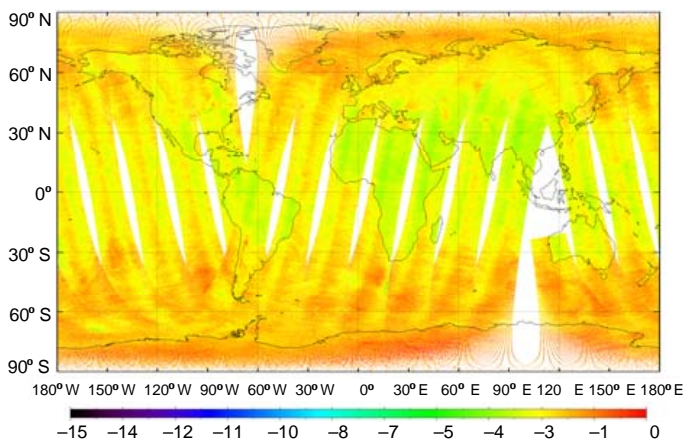

(d)

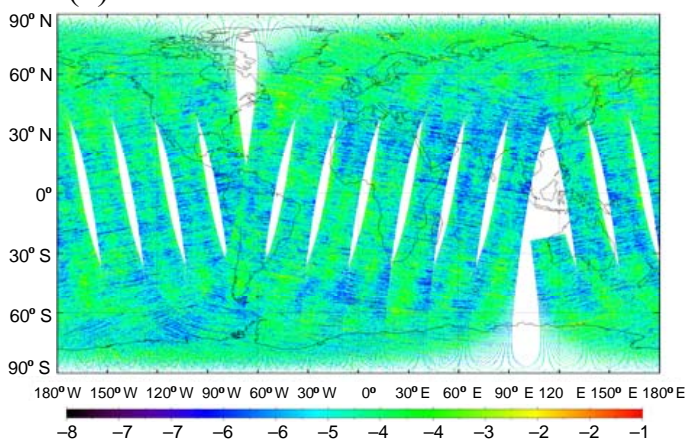

Figure 2. Global distribution of O-B from FY-3C MWTS-2 (a) channel 5, (b) channel 6, (c) channel 7, and (d) channel 8 during 03:0015:00 UTC 1 July 2014.

Table 1. Channel characteristics of FY-3C MWTS-2.

\begin{tabular}{lccc}
\hline Channel number & Center frequency $(\mathrm{GHz})$ & $\begin{array}{c}\text { Weighting function } \\
\text { peak height }(\mathrm{hPa})\end{array}$ & NET $(\mathrm{K})$ \\
\hline 1 & 50.3 & surface & 0.26 \\
2 & 51.76 & surface & 0.20 \\
3 & 52.8 & surface & 0.21 \\
4 & 53.596 & 701.2 & 0.18 \\
5 & 54.40 & 411.1 & 0.19 \\
6 & 54.94 & 308 & 0.19 \\
7 & 55.50 & 194 & 0.23 \\
8 & $57.290344\left(f_{0}\right)$ & 88.5 & 0.74 \\
9 & $f_{0} \pm 0.217$ & 55.3 & 0.66 \\
10 & $f_{0} \pm 0.3222 \pm 0.048$ & 25.49 & 0.49 \\
11 & $f_{0} \pm 0.3222 \pm 0.022$ & 11.97 & 0.53 \\
12 & $f_{0} \pm 0.3222 \pm 0.010$ & 5.75 & 0.93 \\
13 & $f_{0} \pm 0.3222 \pm 0.0045$ & 2.87 & 2.11 \\
\hline
\end{tabular}

age; global and regional assimilation and prediction systems (Chen et al., 2008).

GRAPES 3D-Var (Xue and Chen, 2008; Xue et al., 2008) is the analysis system designed for operational application. The horizontal resolution of GRAPES 3D-Var system is $1^{\circ} \times 1^{\circ}$. The model top is approximately $32 \mathrm{~km}$, with 36 vertical layers. It conducts four data assimilation cycles (00:00,
06:00, 12:00, and 18:00 UTC) and processes six hourly observations, which are centered at 00:00, 06:00, 12:00, and 18:00 UTC. The basic idea of variational assimilation is to find the closest solution to the difference between the effective observation and background field in the given periods under the meaning of the least square method by adjusting the first guess. The GRAPES 3D-Var system analysis is 

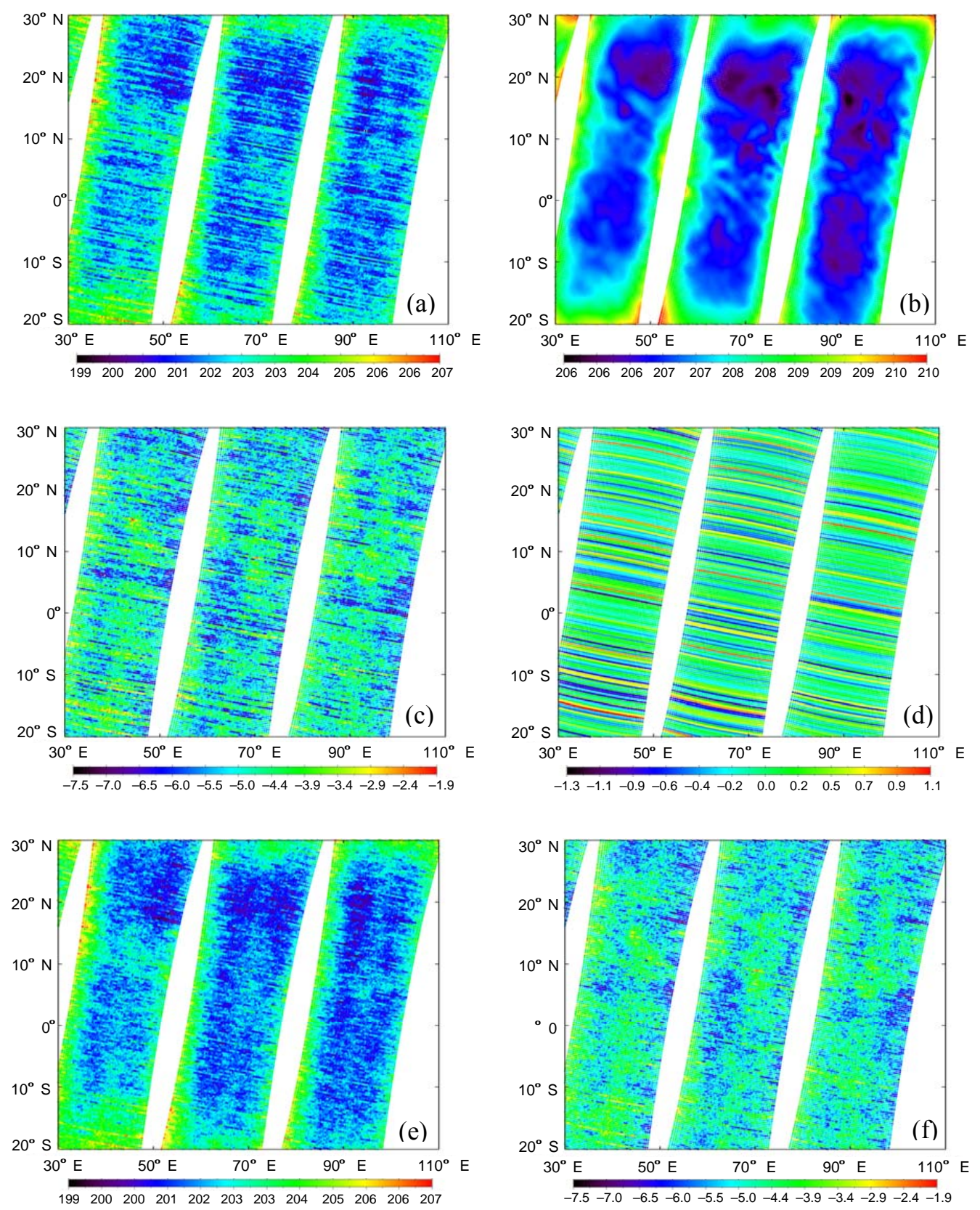

Figure 3. Distribution of (a) observed and (b) model simulated brightness temperature, (c) O-B, (d) striping noise, (e) observed brightness temperature and (f) O-B after removing the striping noise from FY-3C MWTS-2 channel 8 during 03:00-15:00 UTC 1 July 2014.

conducted through the minimization of an objective function given by

$$
\begin{aligned}
J(x) & =J^{\mathrm{b}}+J^{\mathrm{o}}=\frac{1}{2}\left(\boldsymbol{x}-\boldsymbol{x}^{\mathrm{b}}\right)^{T} \mathbf{B}^{-1}\left(\boldsymbol{x}-\boldsymbol{x}^{\mathrm{b}}\right) \\
& +\frac{1}{2}\left(\mathbf{H}(\boldsymbol{x})-\boldsymbol{y}^{\mathrm{o}}\right)^{T} \mathbf{R}^{-1}\left(\mathbf{H}(\boldsymbol{x})-\boldsymbol{y}^{\mathrm{o}}\right),
\end{aligned}
$$

where $\boldsymbol{x}$ is a state vector that is composed of atmospheric and surface variables, $x^{\mathrm{b}}$ is a background estimate of the state vector that is provided by a $6 \mathrm{~h}$ forecast, and $\boldsymbol{y}^{\mathrm{o}}$ is a vector of all of the observations ( $\mathrm{Li}$ and Liu, 2015). $\mathbf{H}$ is the observation operator that transforms the state vector $\boldsymbol{x}$ into observation space. $\mathbf{R}$ is the estimated error covariance of the observations. Currently, the observation errors are considered to be uncorrelated. $\mathbf{B}$ is the estimated error covariance of the background field. The background covariance matrix that was used in this study was estimated using the NMC (National Meteorological Center) method (Parrish and Derber, 1992; Wu et al., 2002), which assumes that the background error covariances are well approximated by averaged fore- 
(a)

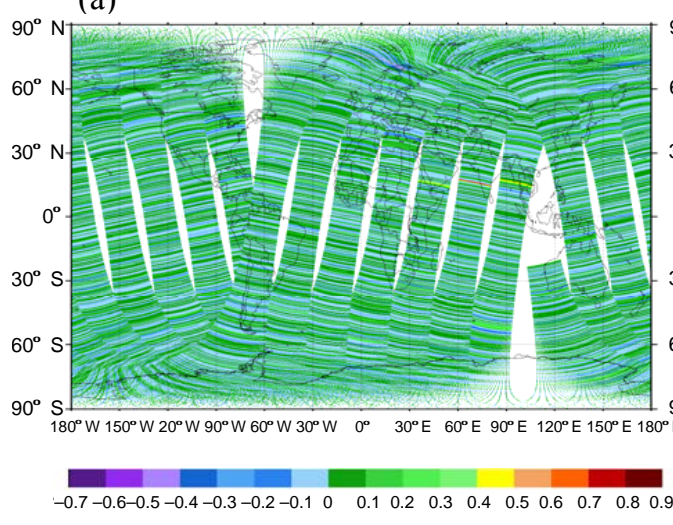

(c)

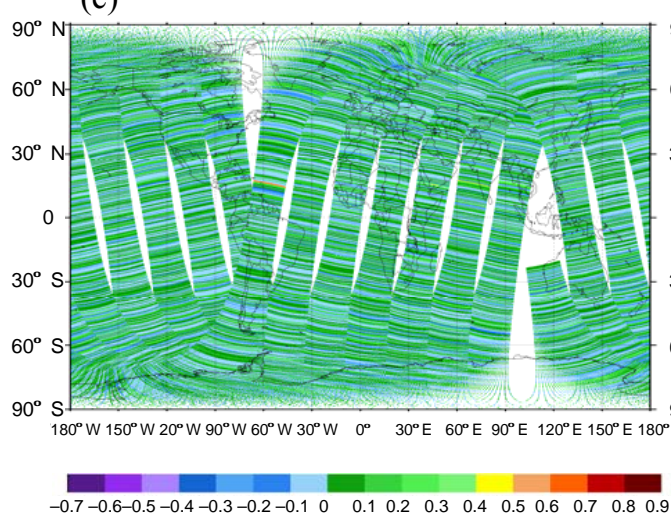

(b)

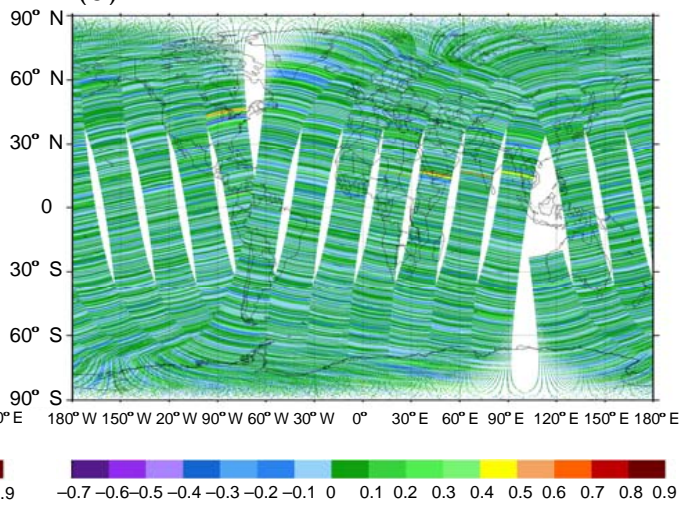

(d)

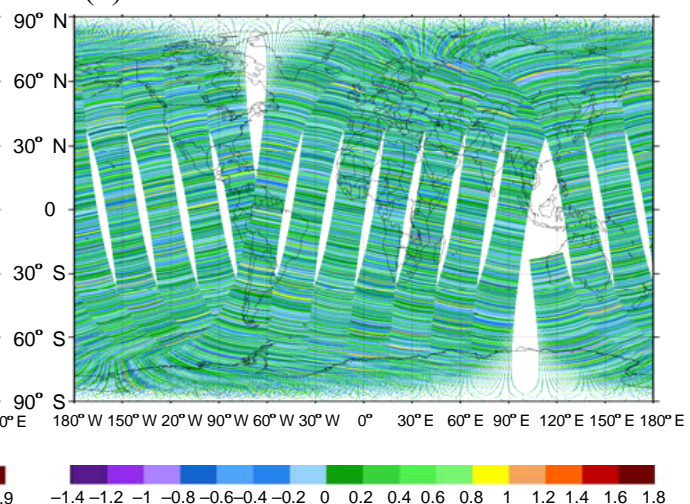

Figure 4. Global distribution of striping noise from FY-3C MWTS-2 (a) channel 5, (b) channel 6, (c) channel 7, and (d) channel 8 during 03:00-15:00 UTC 1 July 2014.

cast differences between $24 \mathrm{~h}$ and $12 \mathrm{~h}$ forecasts, which are calculated using the same initial field.

GRAPES 3D-Var system adopts the incremental analysis method (Courtier et al., 1998). Arakawa C-grid in the horizontal and height-based terrain following coordinate is used in the system. The model variables include wind fields ( $\boldsymbol{u}$, $\boldsymbol{v})$, dimensionless pressure $(\boldsymbol{\pi})$, and specific humidity $(\boldsymbol{q})$. To solve the problem that the inverse of the background error covariance matrix $\left(\mathbf{B}^{-1}\right)$ is too large to be computed, the background term is preconditioned, which improves the convergence in the minimization process and avoids calculating $\mathbf{B}^{-1}$ directly. Empirical orthogonal function (EOF) decomposition is used to separate three-dimensional field into two-dimensional field. A spectral filter is used for the global model as the horizontal component of control variable transform. Optimization adopts the Limited Memory BroydenFletcher-Goldfarb-Shanno method (L-BFGS) (Navon and Legler, 1987). RTTOV 9.3 (radiative transfer for TOVS) has been used for the simulation of satellite radiance (Saunders et al., 1999). Currently, the GRAPES 3D-Var system can directly assimilate radiosondes, surface synoptic observations
(SYNOPs), ship, aircraft report (Airep), atmospheric motion vectors (AMVs), ATOVS, COSMIC RO data, etc.

Prior to this study, GRAPES 3D-Var was not able to assimilate FY-3C MWTS-2 radiance data. In 2014, the fast transmittance coefficients for RTTOV 9.3 were generated by Lu Qifeng in the National Satellite Meteorological Center of CMA. The coefficients were implemented in the RTTOV system to calculate the optical depths. This updated RTTOV 9.3 allows us to assimilate the FY-3C MWTS-2 radiance data in the GRAPES system.

\section{Quality control scheme}

\subsection{Channel selection}

As Table 1 and Fig. 1 illustrate, MWTS-2 channels 1-3 are sensitive to surface and cloud liquid water. Channel 4 mainly profiles lower-troposphere atmospheric temperature. It is also sensitive to the surface and clouds. These channels are not assimilated in this research because model simulations of brightness temperature are still inaccurate due to the un- 

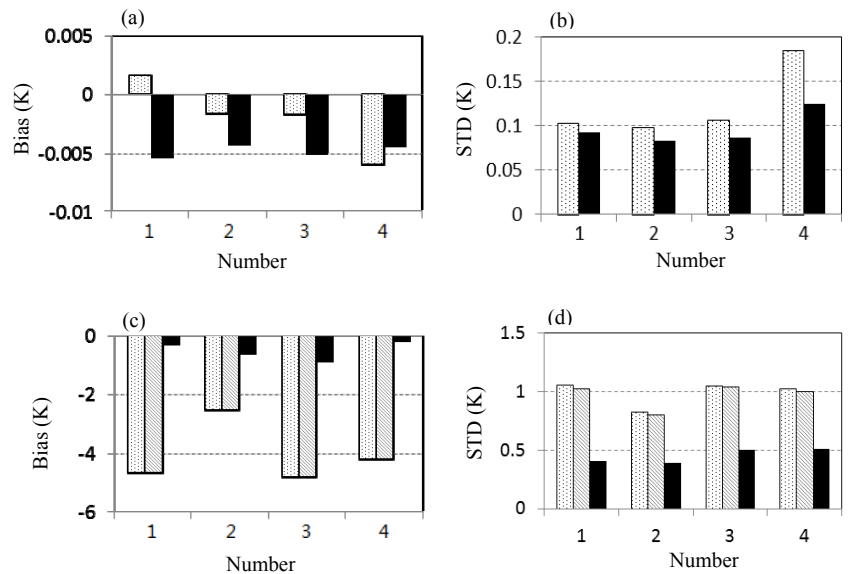

Figure 5. (a) Bias and (b) standard deviation of the striping noise from MWTS-2 channels (dotted bars) and ATMS channels (solid bars) during 1-27 July 2014. The numbers from 1-4 indicate channels 5-8 for MWTS-2 and channels 7-10 for ATMS. (c) Bias and (d) standard deviation of brightness temperature differences between observations and model simulations from MWTS-2 channels before (dotted bars), after (dashed bars) removing the striping noise and ATMS channels (solid bars) after removing striping noise during 1-27 July 2014.

certainty in the surface emissivity. Channels 9-13 are uppertroposphere or lower-stratosphere channels. The assimilation of these channels is sensitive to high-level model atmospheric temperature. However, the model top of GRAPES is approximately $3-4 \mathrm{hPa}$. In some areas, the model top is as low as $7-8 \mathrm{hPa}$. The GRAPES system cannot provide accurate temperature profiles at levels higher than the model top, which are needed for the assimilation of channels 9-13. The use of incorrect extrapolated atmospheric temperature profiles over the model top will ruin the data assimilation. Thus, in the initial experiments, MWTS-2 channels 9-13 are not assimilated. We will try to use them in the next study. In all, MWTS-2 channels 5-8 are used in this research on the GRAPES system.

\subsection{Evaluation of MWTS-2 data and the extraction of the striping noise}

\subsubsection{Evaluation of MWTS-2 data quality}

The global observed brightness temperatures of MWTS-2 channels 5-8 are assessed before they are assimilated in GRAPES. It is found that the striping features are visible in the along-track direction for these channels (global figure omitted; the regional distributions are shown in Fig. 3a). To illustrate the striping noise more clearly, the observations are subtracted by the model simulations. The global differences between MWTS-2 observations and model simulations (OB) are shown in Fig. 2.

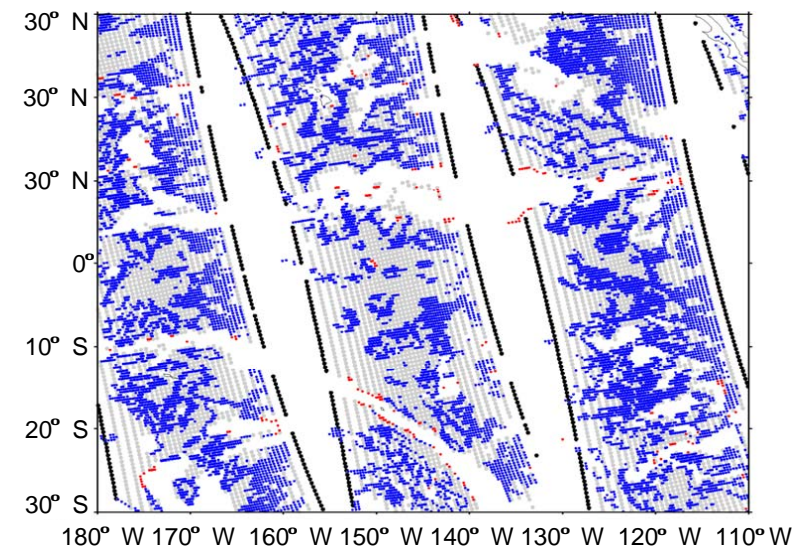

Figure 6. Distribution of the MWTS-2 clear pixels identified by cloud fraction less than $76 \%$ (blue dots) over ocean during the period from 03:00 to 09:00 UTC on 1 July 2014. NOAA-18 AMSU-A FOVs with LWP less than $0.03 \mathrm{~kg} \mathrm{~m}^{-2}$ are shown in grey dots (the FOVs at the scan edge of AMSU-A are in black). The FOVs detected by bi-weighting QC are shown in red.

In this research, the Community Radiative Transfer Model (CRTM 2.0) is used to produce the simulations of brightness temperatures (van Delst et al., 2011). CRTM is chosen here to make the O-B of MWTS-2 comparable to those of ATMS provided by Qin et al. (2013). The $6 \mathrm{~h}$ forecasts of the vertical profiles of temperature, specific humidity and the surface pressure from the NCEP global forecast system (GFS) are used as input to CRTM. The forecast field has a horizontal resolution of $1^{\circ} \times 1^{\circ}$ and 26 vertical levels. The highest vertical level is approximately $10 \mathrm{hPa}$. Global simulations of brightness temperatures are used as a "reference" or "truth" for examining the performance of the MWTS-2 instrument (Zou et al., 2011; Guan et al., 2011).

Figure 2 shows the global distribution of O-B from FY-3C MWTS-2 channels 5-8 during 03:00-15:00 UTC 1 July 2014. The striping phenomena are visible in the alongtrack direction for channels $5-8$. The striping noise is more apparent for channel 8 . The striping noise is embedded in the observations, but the root causes remain to be identified.

\subsubsection{Extracting the striping noise from the MWTS-2 observations}

The evaluation reveals that striping noise is embedded in the MWTS-2 observations. The striping noise needs to be removed from the data without altering the weather signals before assimilating these data (Qin et al., 2013). A technique is used to extract the striping noise from FY-3C microwave radiance observations. This method has been successfully used to derive the striping noise from the ATMS observations without changing weather signals (Qin et al., 2013). It combines principal component analysis (PCA) with ensemble empirical mode decomposition (EEMD). The PCA algo- 
Table 2. Channel selection based on cloud fraction, terrain height (z), and surface types.

\begin{tabular}{lcccc}
\hline Variables & Channel 5 & Channel 6 & Channel 7 & Channel 8 \\
\hline$f_{\text {VIRR }}>76 \%$ & & & $\sqrt{ }$ & $\sqrt{ }$ \\
Land $(z>500 \mathrm{~m})$ & & & $\sqrt{ }$ & $\sqrt{ }$ \\
Land $(z \leq 500 \mathrm{~m})$ & & $\sqrt{ }$ & $\sqrt{ }$ & $\sqrt{ }$ \\
Ocean $(\mathrm{SST}>271.45 \mathrm{~K})$ & $\sqrt{ }$ & $\sqrt{ }$ & $\sqrt{ }$ & $\sqrt{ }$ \\
Ocean $(\mathrm{SST} \leq 271.45 \mathrm{~K})$ & & $\sqrt{ }$ & $\sqrt{ }$ & $\sqrt{ }$ \\
\hline
\end{tabular}

Table 3. Experimental design for the six cycle experiments.

\begin{tabular}{ll}
\hline EXP & Observation data \\
CTRL1 & Conventional data \\
CONV1 & Conventional data + FY-3C MWTS-2 (after removing striping noise) \\
CONV2 & Conventional data + FY-3C MWTS-2 (before removing striping noise) \\
EXP & Observation data \\
CTRL2 & Conventional data + NOAA-15/18 AMSU-A + MetOp-A AMSU-A + COSMIC RO \\
SAT1 & $\begin{array}{l}\text { Conventional data + NOAA-15/18 AMSU-A + MetOp-A AMSU-A + COSMIC RO + FY-3C MWTS-2 } \\
\text { (after removing striping noise) }\end{array}$ \\
SAT2 & $\begin{array}{l}\text { Conventional data + NOAA-15/18 AMSU-A + MetOp-A AMSU-A + COSMIC RO + FY-3C MWTS-2 } \\
\text { (before removing striping noise) }\end{array}$ \\
\hline
\end{tabular}

Notes: Conventional data consists of radiosondes, SYNOP, ship, Airep, AMVs

rithm is used here to characterize sensor noise in the Earth scene data (Tobin et al., 2009). The striping noise is assumed to be constant in the cross-track direction and is contained in the PC coefficients. The EEMD method is used to extract random noise in an along-track varying $\mathrm{PC}$ coefficient $(\mathrm{Wu}$ and Huang, 2009). It is applied to the PC coefficient to extract the first few high-frequency oscillatory components of different channels. By using this technique, the scan dependence in brightness temperature observations is characterized, and the weather signals can be separated from the striping noise when present. The technique combining PCA with EEMD is used to remove the striping noise embedded in MWTS-2 observed brightness temperature.

Figure 3 shows the distributions of observations, model simulated brightness temperature, O-B, detected striping noise from MWTS-2 channel 8 of the tropical portion of the descending swath from 03:00 to 15:00 UTC on 1 July 2014. The observed brightness temperature and O-B after removing the striping noise are also presented in Fig. $3 \mathrm{e}$ and $\mathrm{f}$. It is seen from Fig. 3a and $b$ that striping noise exists in the observations but not in the model simulations. Figure $3 \mathrm{~d}$ shows that on each scan line, the striping noise is the same. After removing the noise shown in Fig. 3d, the channel 8 observed brightness temperature and O-B are displayed in Fig. 3e and f. Comparison of Fig. 3f with $\mathrm{c}$ shows that most of the striping noises are removed in the new O-B data.

The global distributions of the striping noise from MWTS2 channels 5-8 from 03:00 to 15:00 UTC on 1 July 2014 are shown in Fig. 4. The noise is mainly within the range of -0.7 to $0.9 \mathrm{~K}$ for channels $5-7$ and -1.4 to $1.8 \mathrm{~K}$ for channel 8 .
The noise is higher in magnitude in channel 8 than in the other three channels.

Here, an initial comparison of MWTS-2 noise with ATMS noise is conducted. ATMS data are used to compare with the MWTS-2 observations. Figure 5a and b display the bias and standard deviation of the striping noise from MWTS-2 and ATMS channels during 1-27 July 2014, respectively. The numbers from 1-4 indicate channels 5-8 for MWTS-2 and channels 7-10 for ATMS. The center frequencies of ATMS channels 7-10 are very close to those of MWTS-2 channels 5-8. The standard deviations (STDs) of the noise from MWTS-2 channels are slightly larger than that of ATMS corresponding channels. The average biases of the striping noise from MWTS- 2 and ATMS are within $\pm 0.01 \mathrm{~K}$. Figure $5 \mathrm{c}$ and $\mathrm{d}$ show the biases and standard deviations of $\mathrm{O}-\mathrm{B}$ from MWTS-2 channels before and after removing the striping noise and ATMS channels after removing striping noise during 1-27 July 2014. After removing the striping noise, the STDs of O-B from MWTS-2 are decreased. The bias almost does not change. The O-B biases from MWTS-2 are larger than those from ATMS. The STDs of MWTS-2 are also larger than those of ATMS, even after extracting the noise. After the data correction, the MWTS-2 data are used in the data assimilation system.

\subsection{Cloud detection}

Given that the input profiles from the NWP models lack reliable information regarding clouds and because scattering processes cannot currently be accurately simulated in the fast radiative transfer models, the assimilation of cloud- 

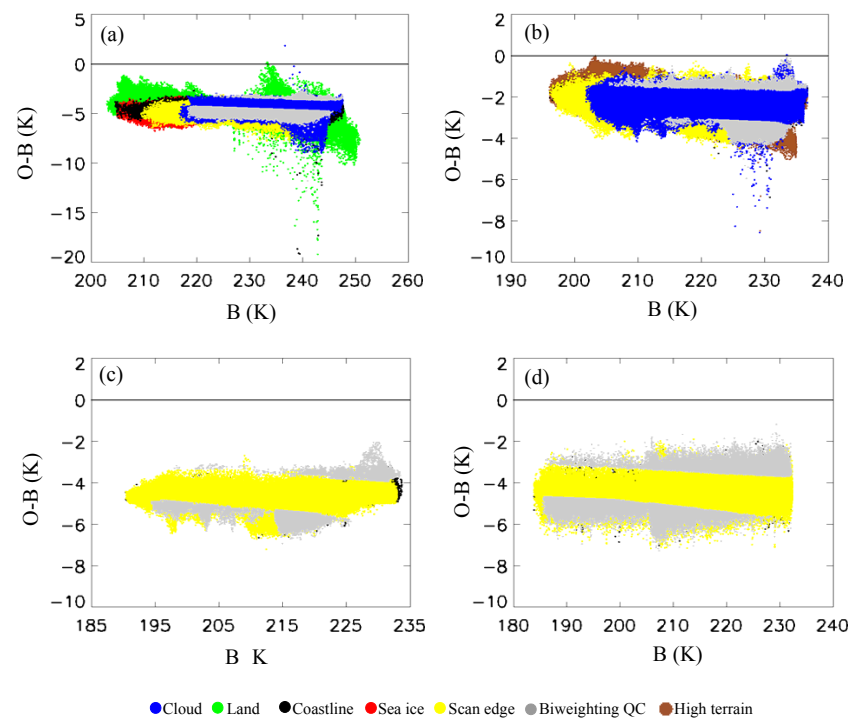

Figure 7. Scatter plots of the differences of brightness temperature between observations and model simulations for MWTS-2 (a) channel 5, (b) channel 6, (c) channel 7, and (d) channel 8 outliers during 1-5 July 2011.

contaminated observations will degrade the assimilation system. As a result, cloud detection should be conducted. For microwave temperature satellite measurements, the two weak water absorption channels $(23.8$ and $31.4 \mathrm{GHz})$ and the channel sounding of the scattering process $(89 \mathrm{GHz})$ are often used for cloud detection (Weng and Grody, 1994; Grody et al., 2001; Klaes and Schraidt, 1999). However, FY3C MWTS-2 does not have these channels. This situation makes it difficult to detect clouds and precipitation by itself. MWTS-1 onboard FY-3A/B also has this problem. To solve this difficulty, in 2013, a VIRR cloud detection method is proposed for FY-3A/B MWTS-1 ( $\mathrm{Li}$ and Zou, 2013; Li and Liu, 2015). It can detect cloud contaminated FOVs efficiently. This method will also be used in this research.

In this scheme, cloud detection for MWTS-2 is conducted using a cloud fraction product from the visible and infrared radiometer (VIRR) onboard the FY-3C satellite. The VIRR has 10 channels spanning the spectrum from 0.455 to $12.5 \mathrm{~mm}$, and the horizontal resolution of the pixel at nadir is $1.1 \mathrm{~km}$. Cloudy FOVs of VIRR are identified by a multithreshold cloud detection method (Li and Zou, 2013). Based on these thresholds, a VIRR pixel is classified as a "cloudy" or "clear" FOV. Then a cloud fraction is calculated for an individual MWTS-2 FOV. This fraction is defined by the ratio of the total number of cloudy pixels to all of the VIRR pixels that are located in the MWTS-2 FOV. A threshold ( $\left.f_{\text {VIRR }}\right)$ of $76 \%$ is demonstrated to be efficient to identify a cloudy scene (Li and Liu, 2015).

Figure 6 shows the distributions of the MWTS-2 clear pixels identified by cloud fractions of less than $76 \%$ over the ocean during the period from 03:00 to 09:00 UTC on
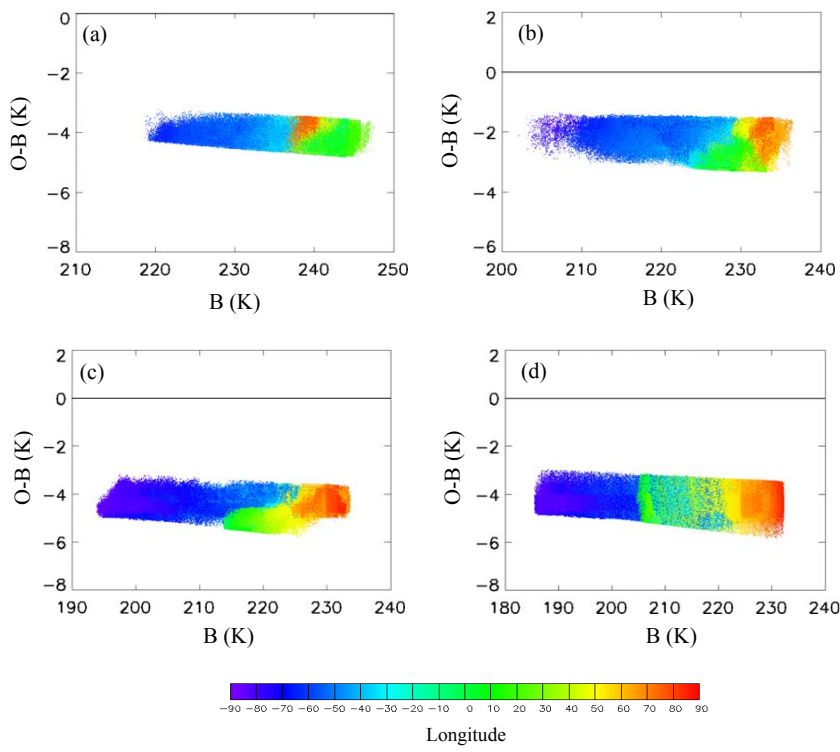

Figure 8. Scatter plots of the differences of the brightness temperature between observations and model simulations for the data of MWTS-2 (a) channel 5, (b) channel 6, (c) channel 7, and (8) channel 8 that have passed quality control during 1-5 July 2014.

1 July 2014. The local equator crossing time of NOAA-18 AMSU-A is close to FY-3C. Thus, the liquid water path (LWP) product of NOAA-18 AMSU-A is used here to verify the precision of the cloud detection scheme. The LWP products from the operational Microwave Surface and Precipitation Products System (MSPPS) are often used in the cloud detection of AMSU-A (Weng and Grody, 1994; Ferraro et al., 2005). The LWP is only retrieved over the ocean (without sea ice) and varies from 0.01 to $2 \mathrm{~kg} \mathrm{~m}^{-2}$. An AMSU-A FOV with an LWP greater than a threshold $\left(f_{\mathrm{LWP}}\right)$ of $0.03 \mathrm{~kg} \mathrm{~m}^{-2}$ is marked as a cloudy scene in $\mathrm{Li}$ and Liu (2015).

FOVs with LWPs less than $0.03 \mathrm{~kg} \mathrm{~m}^{-2}$ (Li and Liu, 2015) are shown as grey dots (the FOVs at the scan edge of AMSUA are in black). As illustrated in Fig. 6, the clear FOVs are almost all located in the grey dot region, corresponding to the clear region identified by an AMSU-A LWP of less than $0.03 \mathrm{~kg} \mathrm{~m}^{-2}$. The red dots show the MWTS-2 data that pass the cloud detection but are removed by the next QC step biweighting QC (described in the next section). It is seen that these dots are distributed at the edge of the cloudy region identified by AMSU-A. This suggests that although some cloudy FOVs are not detected by the VIRR method, they will be removed in the next QC step (bi-weighting QC).

\subsection{QC based on scan and surface characteristics}

In addition to clouds, surface emissivity causes another type of challenge for satellite data assimilation. Surface emissivity varies with frequency and surface type. The global distribution of surface emissivity is not well known. Simula- 

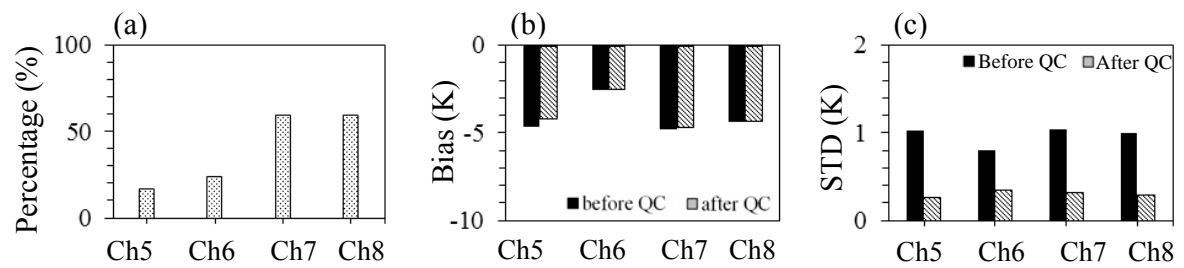

Figure 9. (a) Percentages of the MWTS-2 data that passed QC during 1-27 July 2014. (b) Global biases and (c) standard deviations of O-B before (solid bars) and after (dashed bars) quality control during 1-27 July 2014.

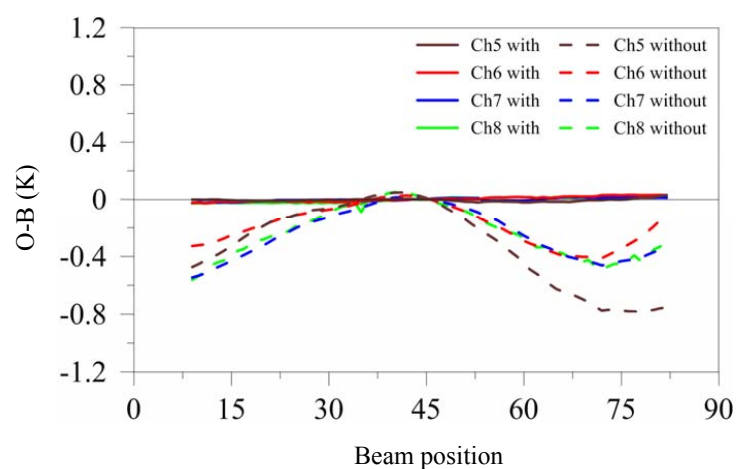

Figure 10. Averaged scan bias with (solid lines) and without (dashed lines) bias correction for MWTS-2 during 1-27 July 2014.

tions of surface-sensitive channels contain large errors, especially over land, snow, ice, and coastal areas. The large uncertainty in the surface emissivity and the significant impact of surface emissivity on the radiance simulations also make the detection of cloud/precipitation considerably more difficult over land, snow, ice, and coastal areas. Additional QC steps addressing problems associated with surface emissivity, high terrain and outliers are implemented for FY-3C MWTS-2 data.

Table 2 provides a QC scheme for the MWTS-2. When $f_{\text {VIRR }}$ is greater than $76 \%$, only data from channels $7-8$ are used because the weighting function of this channel range is in the upper-troposphere where clouds have negligible effects. Channel 5 is used only over the ocean when no sea ice is present. The first reason is that the O-B departures of channel 5 over sea ice (over Antarctic and arctic) are larger than those over the ocean. The second is that the weighting function (Fig. 1) of channel 5 shows that there are some surface signals observed by channel 5 . However, simulations of surface signals are not good for GRAPES (inaccurate surface temperature and surface emissivity). Only the data over ocean are used in this initial study. The MWTS2 channel 5 over land and channel 6 over high terrain (e.g., terrain altitude higher than $500 \mathrm{~m}$ ) are not used due to the same reason. The number of 500 is based on the previous experience. The quality control of channel 7 observations of AMSU-A and channel 3 of MWTS- 1 onboard FY-3A/B
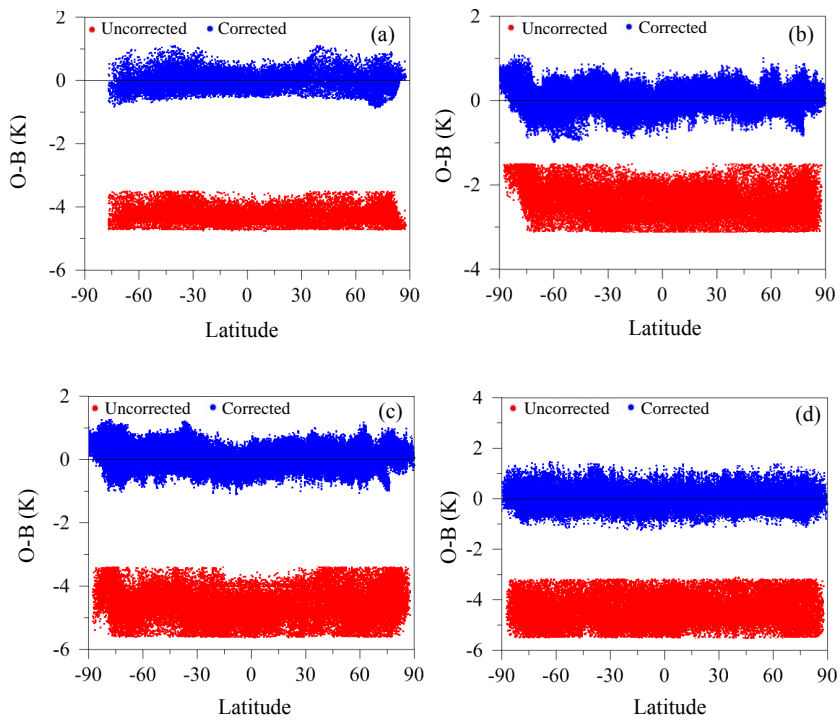

Figure 11. Scatter plots of uncorrected (red) and corrected (blue) $\mathrm{O}$ B with latitude for MWTS-2 (a) channel 5, (b) channel 6, (c) channel 7, and (d) channel 8 during 1-5 July 2014.

adopts this threshold, so we still use it to maintain the consistency. The identification of an underlying land/sea/coast is based on a land mask database with about $15 \mathrm{~km}$ resolution. Sea ice is identified when sea surface temperature (SST) is less than $271.45 \mathrm{~K}$ using CMA daily SST data. The eight outermost FOVs (i.e., FOV 1-8, 83-90) for all channels are excluded for data assimilation due to larger inhomogeneity limb-effects that could not be accurately accounted for in forward radiative transfer models. The data are thinned into a $120 \mathrm{~km}$ box.

After the previous QC procedures, a bi-weighting quality control procedure is applied to identify outliers. The outliers are defined as those measurements whose values deviate from model-simulated values by more than $Z_{\text {score }}$ times the standard deviation (Lansante, 1996; Zou and Zeng, $2006)$. Firstly, the biweight mean $\left(\mu_{\mathrm{bm}}\right)$ and biweight standard deviation $\left(\sigma_{\mathrm{bsd}}\right)$ of the following variable are calculated (Lansante, 1996; Zou and Zeng, 2006): 

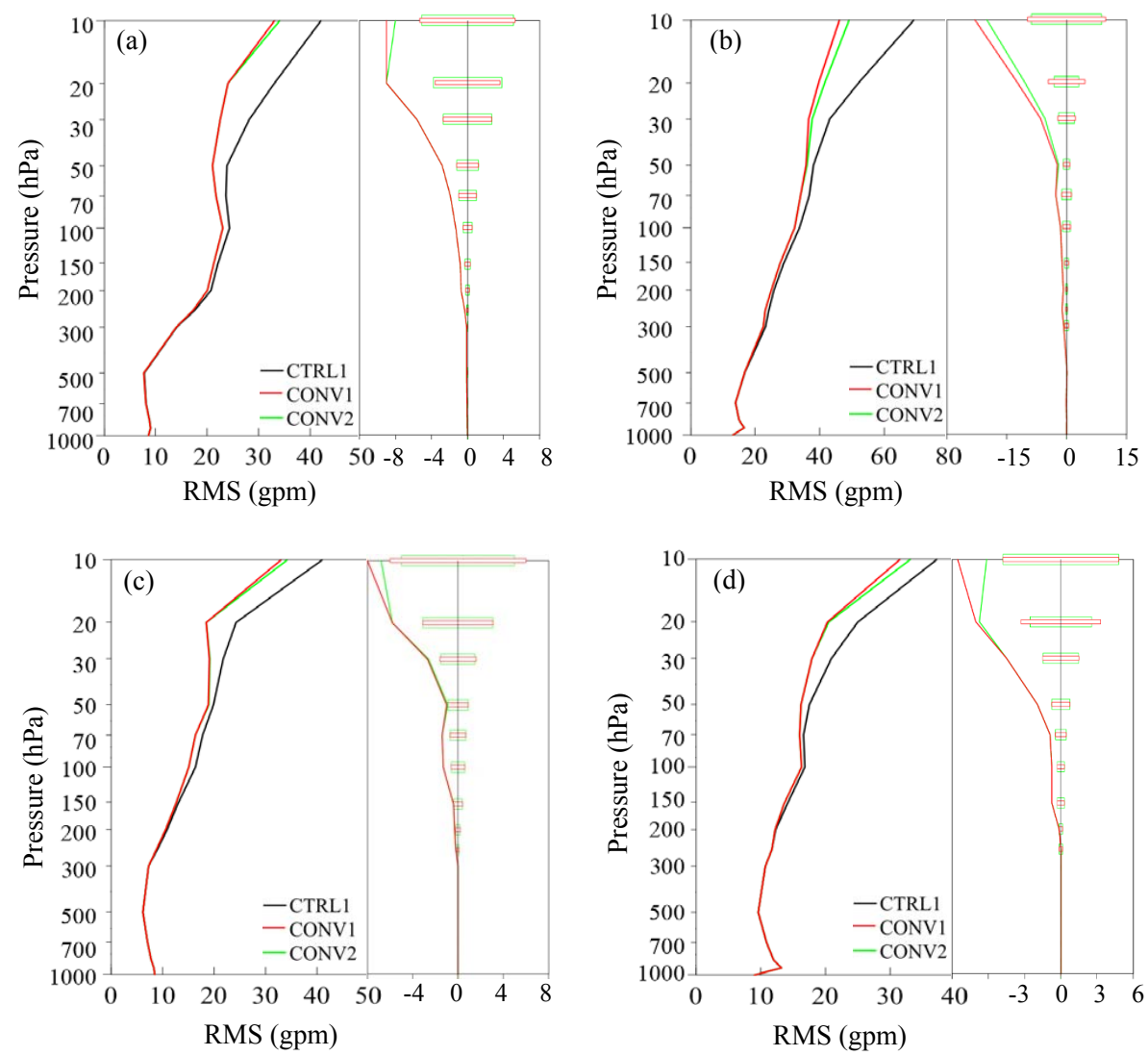

Figure 12. RMS of geopotential height from the analysis field difference between CTRL1 and NCEP (black), CONV1 and NCEP (red), CONV2 and NCEP (green) in the (a) Northern Hemisphere, (b) Southern Hemisphere, (c) the tropics, and (d) East Asia during 127 July 2014. The statistical significance testing of CONV1 and CTRL1 (CONV2 and CTRL1) are shown in the right part of each figure in red (green). The RMS differences outside of outline bars are significant at the $95 \%$ confidence level.

$x \equiv \frac{\Delta T_{\mathrm{b}}}{T_{\mathrm{b}}^{\mathrm{bg}}}=\frac{T_{\mathrm{b}}^{\mathrm{obs}}-T_{\mathrm{b}}^{\mathrm{bg}}}{T_{\mathrm{b}}^{\mathrm{bg}}}$,

where $T_{\mathrm{b}}^{\mathrm{obs}}$ and $T_{\mathrm{b}}^{\mathrm{bg}}$ represent the observed and modelsimulated brightness temperature, respectively. Here the biweight mean and biweight standard deviation are similar to the traditional mean and standard deviation except that the impact of outliers to their values is minimized. Then, a $Z$ score for all data that pass all the checks on cloud, terrain height and surface types is calculated:

$Z_{i}=\frac{x_{i}-\mu_{\mathrm{bm}}}{\sigma_{\mathrm{bsd}}}$,

where the subscript " $i$ " indicate the $i$ th data. Data with a Zscore of more than 2 are removed. Considering the variations of the mean states of the atmosphere at different latitudes, the bi-weighting quality control is implemented in three separate latitudinal bands separately: tropics $\left(30^{\circ} \mathrm{N}-30^{\circ} \mathrm{S}\right)$, middle latitudes $\left(30-60^{\circ} \mathrm{N}, 30-60^{\circ} \mathrm{S}\right)$, and high latitudes $(60-$ $\left.90^{\circ} \mathrm{N}, 60-90^{\circ} \mathrm{S}\right)$.

\section{Assimilation results}

\subsection{Experimental setup}

Initially, four different experiments are conducted from 1 to 27 July 2014. Control run 1 (CTRL1) assimilates only conventional observations. The conventional observations contain a global set of surface and upper-air reports, including radiosondes, SYNOP, ship, Airep, and AMVs from the Global Telecommunications System (GTS). Control run 2 (CTRL2) assimilates conventional observations, NOAA15/18, AMSU-A, MetOp-A AMSU-A, and COSMIC RO observations. The setup for the experimental run (CONV1 and SAT1) is identical to the control run (CTRL1 and CTRL2) except that the FY-3C MWTS-2 radiance data are used after first removing the striping noise. Table 3 shows the experimental design for the four-cycle experiments.

The CTRL1, CONV1, CTRL2, and SAT1 experiments are conducted to reveal the impact of MWTS-2 on the global GRAPES system. In addition, CONV2 and SAT2 experiments are also conducted to demonstrate the impact of the 

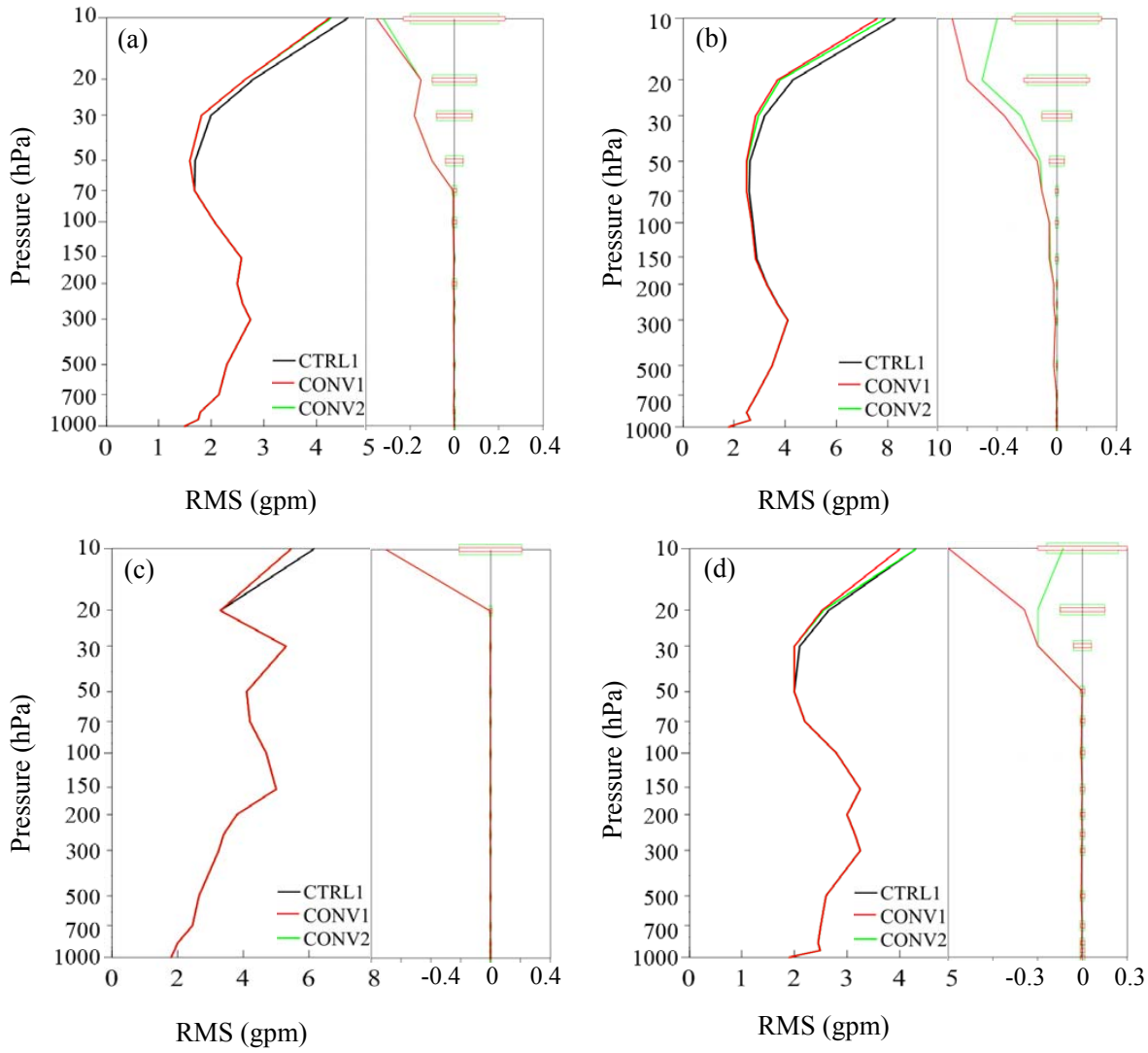

Figure 13. Same to Fig. 12 but for RMS of U wind.

extraction of striping noise on the GRAPES 3D-Var analysis.

\subsection{Analysis/forecast cycle experiments}

\subsubsection{Data characteristics after QC and bias correction}

The quality control scheme of MWTS-2 described in Sect. 3 is implemented in the four impact experiments (CONV1, CONV2, SAT1, and SAT2). The quality control procedures are the same for the four experiments. The quality control procedures of SAT1 are displayed in Figs. 7-11.

Figure 7 shows scatter plots of the differences of brightness temperature between observations and model simulations for the outliers of MWTS-2 channels 5-8 during 15 July 2014. Only clear observations over the ocean are retained for channel 5. Some channel 6 radiance data over land with a low terrain altitude remain. These data can contribute to the NWP analysis and forecast over land. The biweighting quality control procedures remove some residual cloudy FOVs that have passed the cloud detection scheme. As indicated in Fig. 6, the observations that are removed by the bi-weighting QC are typically located near cloudy FOVs. These outliers are probably associated with those observations that are affected by clouds and precipitation. The O-B differences of the outliers and their variations are much larger than those of the remaining data.

Figure 8 displays scatter plots of the differences of the brightness temperature between observations and model simulations for the data of MWTS-2 channels 5-8 that have passed quality control during $1-5$ July 2014 . The differences between the MWTS- 2 observations and the model simulations for channel 5 are within the range of -3.8 to $-4.5 \mathrm{~K}$ (Fig. 8a). The variation range of channel 6 is from -1.8 to $-3 \mathrm{~K}$. The observations minus simulations of channels 7-8 vary in the range from -3 to $-5 \mathrm{~K}$. After the $\mathrm{QC}$ procedure, the biases vary within a smaller range for the four channels.

On average, approximately 17, 25, 60 and $60 \%$ of the global observations remain for channels 5-8, respectively (Fig. 9a). More outliers are identified for channel 5 because it is a lower-level sounding channel and the observations are contaminated by clouds and the surface. The mean global biases and standard deviations of O-B are shown in Fig. 9b and $\mathrm{c}$, both with and without removing the outliers. All of these channels have negative biases before and after QC. After QC, the biases and STDs of all channels are all reduced. The remaining biases of channels 5-8 are approximately $-4.2,-2.5,-4.6$ and $-4.2 \mathrm{~K}$, respectively. The STDs are approximately $0.2 \mathrm{~K}$ for these four channels. These biases 

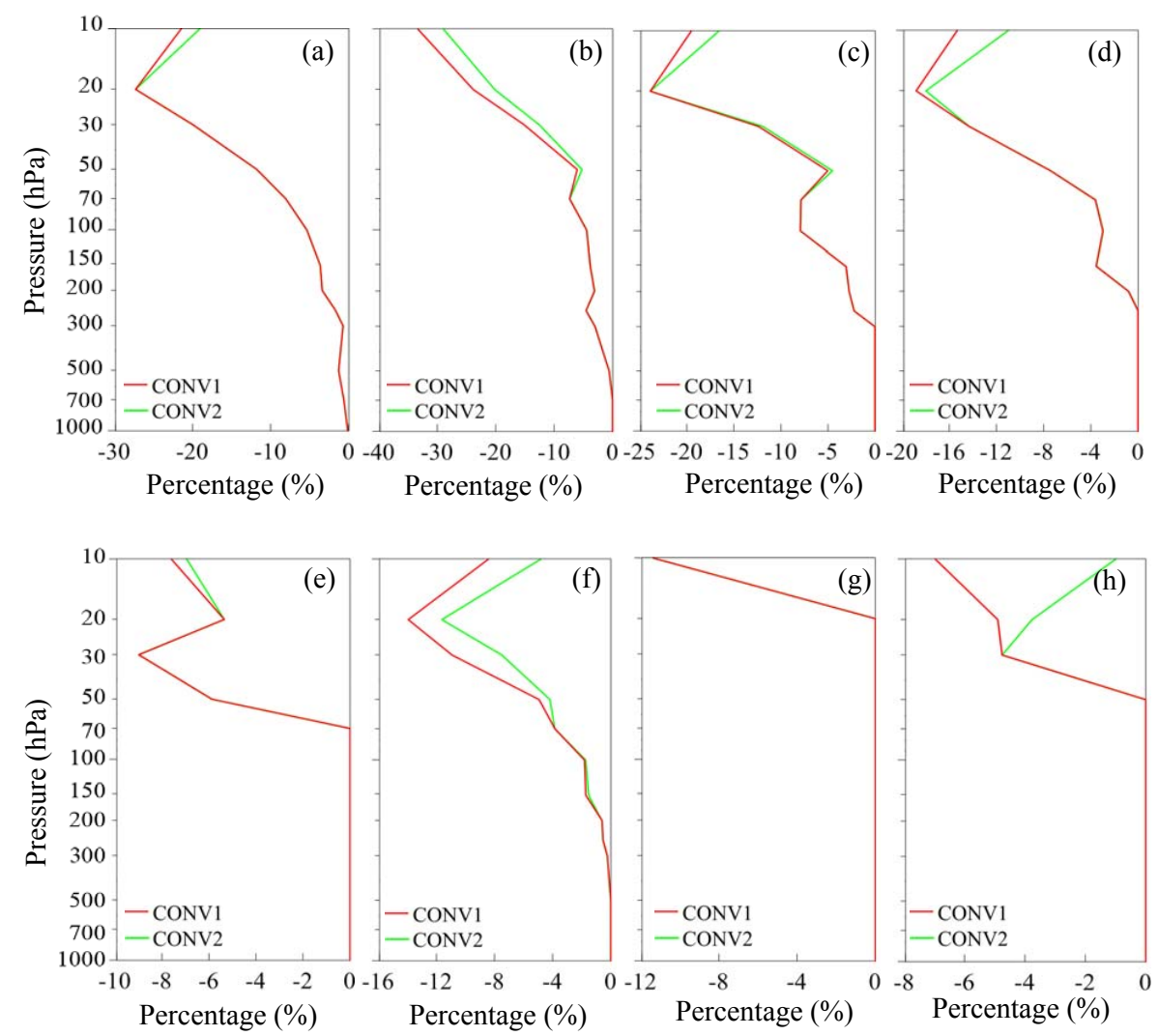

Figure 14. The reduction percentage of CONV1 (red) and CONV2 (green) relative to CTRL1 in the geopotential height RMS of the analysis field difference with NCEP in (a) Northern Hemisphere, (b) Southern Hemisphere, (c) the tropics, and (d) East Asia during 1-27 July 2014. (e)-(h) are similar to (a)-(d) but for U wind.

will be removed by the subsequent bias-correction procedures.

Data assimilation schemes assume unbiased O-B. However, the bias between observed and first-guess radiance always exists due to the inaccuracies in RTTOV, the error in the calibration of the satellite instrument, and the error in the first-guess model profiles of temperature and humidity. To assimilate the MWTS-2 radiance data, bias correction is an essential step. The biases are calculated using an empiric bias-correction method provided by Harris and Kelly (Harris and Kelly, 2001). The biases are then subtracted from the MWTS-2 observations.

Figure 10 shows the average uncorrected scan bias and the corrected scan bias for MWTS-2 during 1-27 July 2014. After bias correction, the scan biases are almost removed. Figure 11 shows scatter plots of uncorrected and corrected O-B with latitude for MWTS-2 channels 5-8 during 15 July 2014 . The biases of O-B are significantly reduced. The average biases after the bias correction are within $\pm 0.1 \mathrm{~K}$.

\subsubsection{Analysis and forecast}

The analysis fields of these experiments are first verified against those of the NCEP analysis.
The observation errors of MWTS-2 are shown in Table 4 . They are estimated using statistics of observed-minusforecast radiance departures. Currently, fixed values of 0.3 , $0.35,0.35$ and $0.35 \mathrm{~K}$ are applied for channels 5-8 respectively. The impacts of MWTS- 2 on the control experiment that assimilates only conventional data are shown in Figs. 12 and 13. These figures display the root mean square (RMS) of the geopotential height and $\mathrm{U}$ wind from the analysis field difference between CTRL1 and NCEP, between CONV1 and NCEP, and between CONV2 and NCEP in the Northern Hemisphere, the Southern Hemisphere, the tropics, and East Asia during 1-27 July 2014. The figures indicate that the root mean squares of geopotential height and the wind field from the CONV1 and CONV2 analysis field are smaller than those of CTRL1. This suggests that if adding MWTS-2 observations in the assimilation system, the RMS of the analysis field will be reduced. The RMS differences outside of outline bars are significant at the $95 \%$ confidence level. These figures show that most results have passed the confidence test of $95 \%$ confidence level. To make the difference more clear, the reduction percentages of CONV2 (red) and CONV1 (green) relative to CTRL1 in the geopotential height RMS are shown in Fig. 14. As the weighting function peak heights of MWTS- 

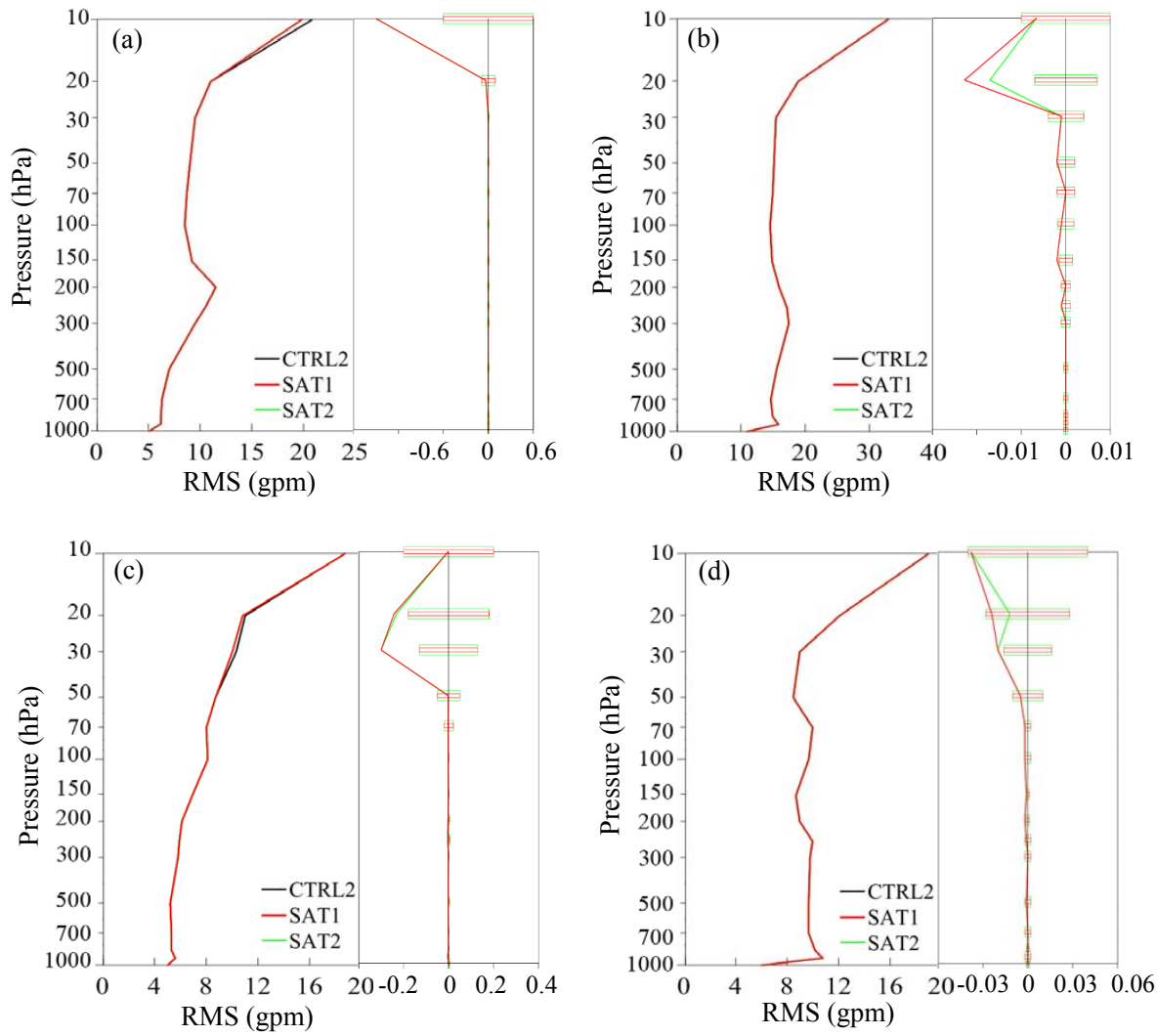

Figure 15. (a) RMS of geopotential height from the analysis field difference between CTRL2 and NCEP (black), SAT1, and NCEP (red), SAT2 and NCEP (green) in the (a) Northern Hemisphere, (b) Southern Hemisphere, (c) the tropics, and (d) East Asia during 1-27 July 2014. The statistical significance testing of SAT1 and CTRL2 (SAT2 and CTRL2) are shown in the right part of each figure in red (green). The RMS differences outside of outline bars are significant at the $95 \%$ confidence level.

Table 4. The given observation errors (K) of AMSU-A (numbers 1-7 indicate AMSU-A channels 5-11) and MWTS-2 (numbers 2-5 indicate MWTS-2 channels 5-8) in GRAPES system.

\begin{tabular}{lcrrrr}
\hline Number & Center frequency $(\mathrm{GHz})$ & NOAA-15 AMSU-A & NOAA-18 AMSU-A & MetOp-A AMSU-A & FY-3C MWTS-2 \\
\hline 1 & 53.596 & 0.28 & 0.28 & 0.28 & \\
2 & 54.4 & 0.2 & 0.22 & 0.2 & 0.3 \\
3 & 54.94 & 0.22 & 0.22 & & 0.35 \\
4 & 55.5 & 0.22 & 0.24 & 0.21 & 0.35 \\
5 & $57.290344\left(f_{0}\right)$ & 0.2 & 0.22 & 0.2 & 0.35 \\
6 & $f_{0} \pm 0.217$ & 0.25 & 0.25 & 0.25 & \\
7 & $f_{0} \pm 0.3222 \pm 0.048$ & 0.35 & 0.35 & 0.35 & \\
\hline
\end{tabular}

2 channels $5-8$ are within the range of 411.1 to $88.5 \mathrm{hPa}$, the maximum impact of the MWTS-2 radiance is observed in the mid-upper level field (lower than $400 \mathrm{hPa}$ ). With the assimilation of MWTS-2 radiance data, the RMS of geopotential height in the upper level is significantly decreased. Comparison between CONV1 and CONV2 shows that after removing striping noise, the RMS of the analysis field is slightly reduced, especially in the upper level. This suggests that the quality control technique of removing striping noise can slightly decrease the analysis error. The results of the im- pact on the bias of geopotential height and $\mathrm{U}$ wind are similar to those on root mean square (figure omitted).

The impacts of MWTS-2 radiance on the GRAPES system when assimilating both conventional data and satellite data are also assessed. Figures 15-16 are similar to Figs. 1213 but for CONV2, SAT1, and SAT2. The reduction percentages of SAT2 (green) and SAT1 (red) relative to CTRL2 in the geopotential height RMS are shown in Fig. 17.Overall, the impact is neutral, with the three lines almost overlapping in all regions. The results of the impact on the temperature 

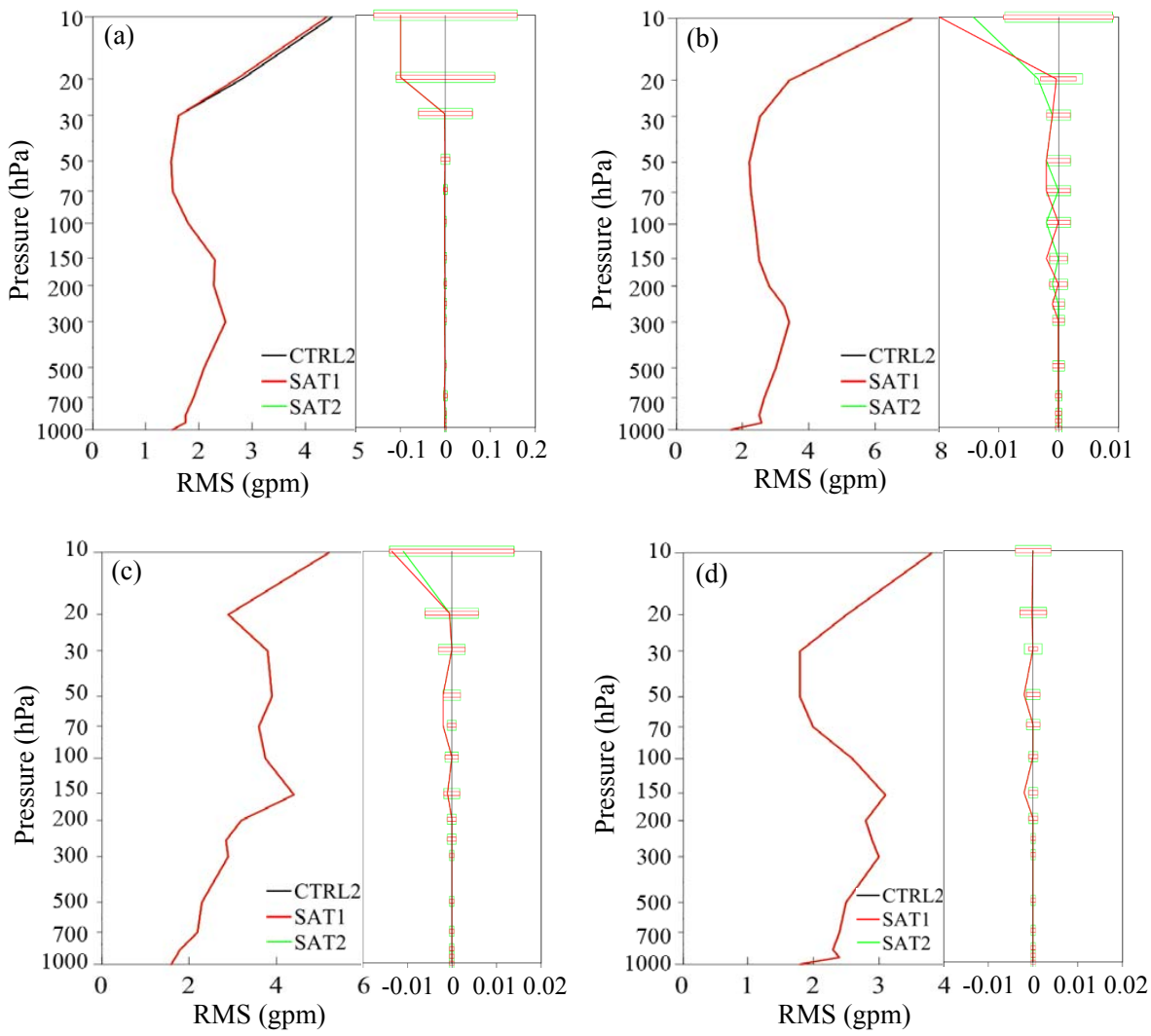

Figure 16. Same to Fig.15 but for RMS of U wind.

field are similar to those on the geopotential height and wind fields.

Finally, the forecasts are verified against their own analyses. An overall measurement of the quality of mediumrange forecasts for predicting a large-scale weather system is widely given by the anomaly correlation coefficient (ACC) of a $500 \mathrm{hPa}$-height forecast field. A key performance indicator for the forecast system is the forecast range at which the ACC decreases to $60 \%$. Seven-day forecasts are produced for each day of the 27-day period in this study. Figures 18 and 19 show mean ACC and RMS of $500 \mathrm{hPa}$ geopotential height of CTRL1, CONV1, and CONV2 experiments in the Northern Hemisphere and the Southern Hemisphere for the period from 1 to 27 July 2014. Figure 14 also shows the results of the significance test. The differences between CONV1 and CTRL1 (CONV1-CTRL1) and between CONV2 and CTRL1 (CONV2-CTRL1) are analyzed. The ACC and RMS differences outside of outline bars are significant at the $95 \%$ confidence level. These figures show that most results have passed the confidence test of $95 \%$ confidence level. In the Northern Hemisphere and the Southern Hemisphere, the average ACC of CONV1 is higher than the control experiment CTRL1, and the RMS of CONV1 is lower than that of CTRL1. The MWTS-2 observations show positive impact only when conventional data are assim- ilated in the GRAPES system. The lines of CONV2 are almost overlapped on CONV1 in the Northern Hemisphere. In the Southern Hemisphere, the RMS of $500 \mathrm{hPa}$ geopotential height of CONV1 is slightly smaller than that of CONV2. The forecast error is slightly decreased. It suggests that the quality control scheme of extracting striping noise may contribute to the analysis and forecast. This impact will be further explored.

We also run a CONV3 experiment to have a comparison between the impact of AMSU-A and MWTS-2. Observations from AMSU-A onboard NOAA-15/18 and MetOp-A are added to the control experiments (CTRL1). AMSU-A channels 5-11 are used. The channel frequencies of AMSUA are similar to MWTS-2 channels 4-10. The Harris and Kelly scheme is used to correct the bias of AMSU-A (Harris and Kelly, 2001). Cloudy FOVs over ocean are identified using the scatter index (SI) method (Klaes and Schraidt, 1999). The scatter index is defined by the difference between AMSU-A channel 15 observations and a physical retrieval derived AMSU-A channel 15 simulation using a linear regression model between AMSU-A channel 15 and AMSU-A channels 1, 2, and 3 observations over the ocean. A FOV is identified as cloud contaminated if SI is over 15. Over land, FOV is identified to be cloudy when the O-B is over $2 \mathrm{~K}$. Other QC steps are conducted in the following order: 

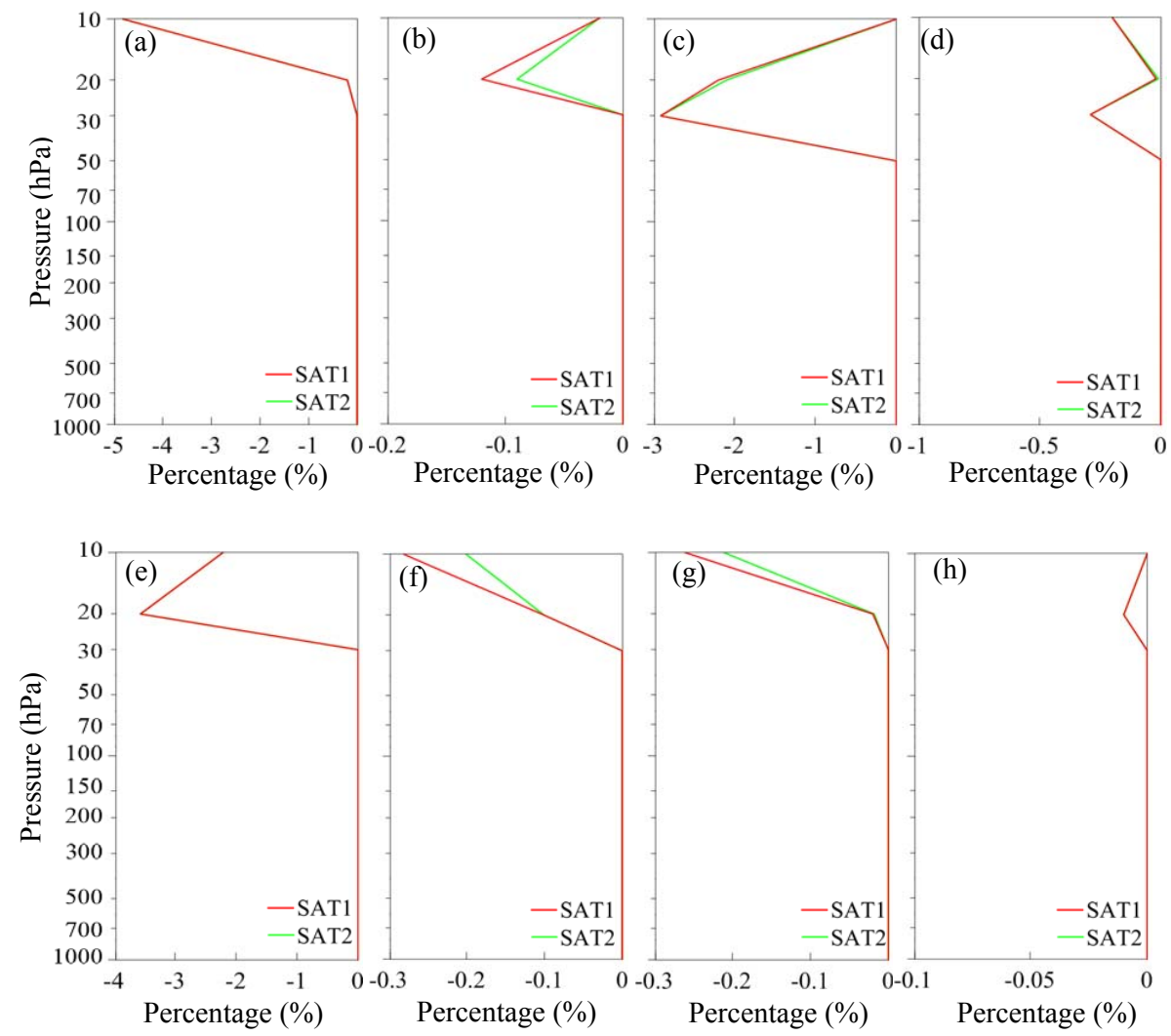

Figure 17. Same to Fig. 14 but for CTRL2, SAT1, SAT2.

(i) coastal FOVs are removed, (ii) three outmost FOVs are not used, (iii) channel 5 and channel 6 over sea ice and land are not used, (iv) channel 7 observations are not used if the terrain altitudes are higher than $500 \mathrm{~m}$, and (v) outliers with large differences between observations and model simulations are removed. After these quality control, about 27, $28,37,73,73,73$ and $70 \%$ of the observations are maintained for channels 5-11. The percentages are much higher than MWTS-2 channels. Maybe one of the reasons is that the cloud detection method for MWTS-2 removes too much data. The given observation errors of AMSU-A are shown in Table 4 . They are smaller than those of MWTS- 2 channels. The data are thinned into a $120 \mathrm{~km}$ box. The verification results are shown in Fig. 18. The impacts of AMSU-A are more obvious than MWTS-2. Because AMSU-A uses more data than MWTS-2 and the observation error is set to be smaller, the results seem reasonable.

Figure 19 is similar to Fig. 18 but for the experiments of CTRL2, SAT1, and SAT2. The experimental results of SAT1 are almost equal to those of SAT2, with the lines almost overlapping in both hemispheres. Most results do not pass the confidence test of $95 \%$ confidence level. Upon comparing SAT1 and SAT2 with CTRL2, it is found that the impact of MWTS-2 on the assimilation system when conventional data and other satellite data are used is negligible. In the SAT1 and SAT2, the total amount of AMSU-A observations assimilated is about 6.7 times of that of MWTS-2. Considering the large number difference between AMSU-A and MWTS-2, the neutral result is not surprising.

Overall, adding MWTS-2 observations in an assimilation system that assimilates only conventional data can slightly improve the analysis and forecast. The quality control scheme of extracting striping noise may contribute to the analysis and forecast. The MWTS-2 impact on the assimilation system that assimilates all data is neutral.

\section{Summary and discussion}

In this research, the assimilation of the FY-3C MWTS-2 radiance data in the Chinese NWP system-Global GRAPES system is conducted. A quality control procedure for FY-3C MWTS-2 is proposed and applied in the GRAPES system. Through the initial assessment of MWTS-2 observations, an apparent striping pattern is found in the observed brightness temperature. A technique combining PCA and EEMD is used to extract the striping noise. After the method is applied to the observations, most of the striping noise is removed. A quality control scheme is introduced based on the characteristics of the FY-3C MWTS-2 observations. A cloud-detection al- 

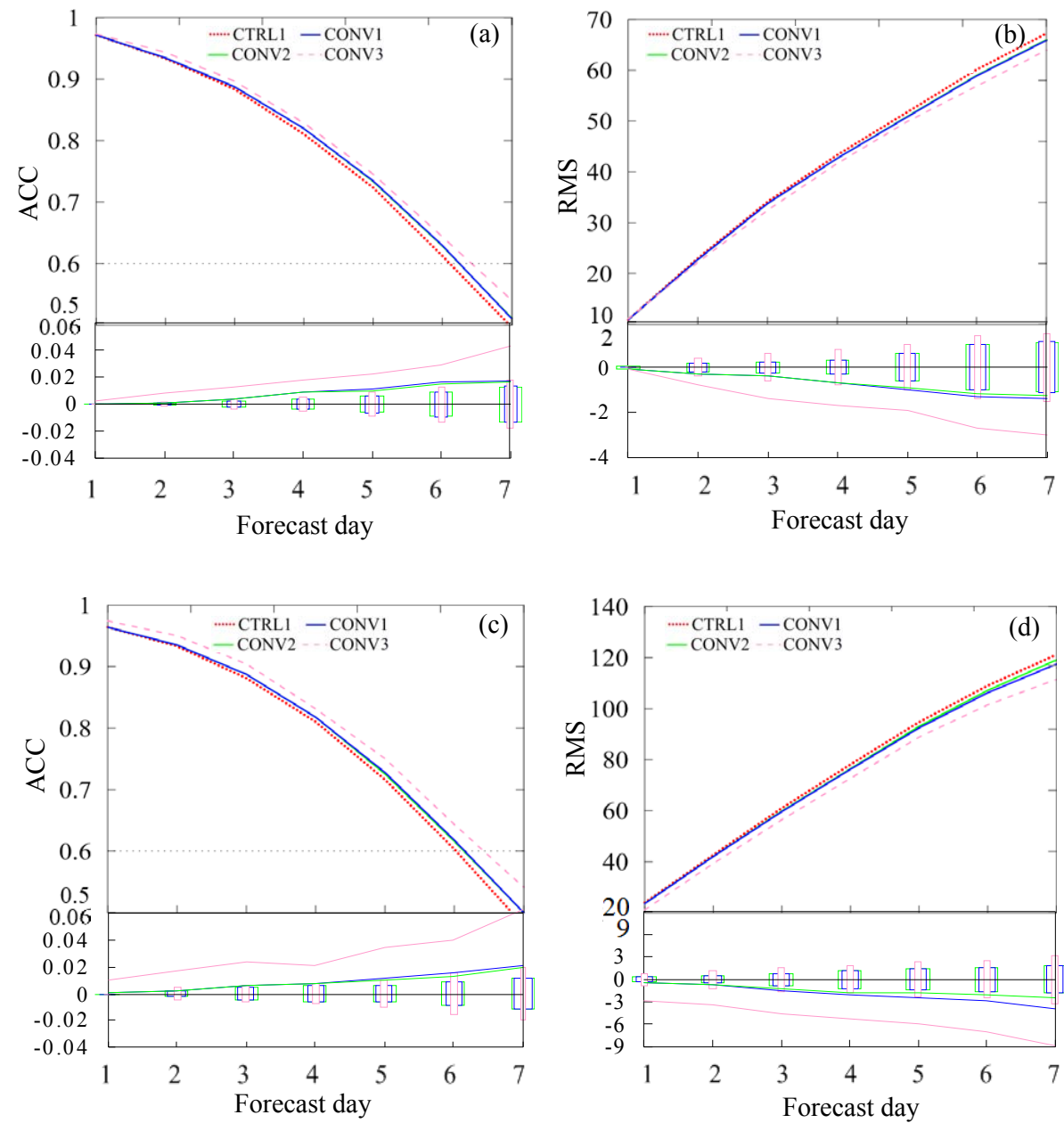

Figure 18. Mean ACC (left panels) and RMS (right panels) of $500 \mathrm{hPa}$ geopotential height of CTRL1 (red dashed line), CONV1 (blue solid line), CONV2 (green solid line) and CONV3 (pink dashed line) experiments in (a-b) the Northern Hemisphere and (c-d) the Southern Hemisphere for the period from 1 to 27 July 2014. The statistical significance testing of CONV1 and CTRL1, CONV2 and CTRL1, CONV3, and CTRL1 are shown in the lower part of each figure in blue, green, and pink. The ACC and RMS differences outside of outline bars are significant at the $95 \%$ confidence level.

gorithm with a threshold of $76 \%$ is incorporated based on the cloud fraction product that is provided by the VIRR onboard FY-3C. Other QC steps are based on the underlying surface characteristics and the differences between model simulations and observations. The bi-weighting QC can remove some residual cloudy FOVs that have passed the clouddetection scheme. Approximately $83,75,40$, and $40 \%$ of the MWTS-2 observations are removed by the proposed QC for channels 5-8, respectively. After QC, the standard deviations of O-B decrease significantly. The remaining biases of channels $5-8$ are approximately $-4.2,-2.5,-4.6$ and $-4.2 \mathrm{~K}$, respectively. The STDs are approximately $0.2 \mathrm{~K}$ for these four channels. These biases are removed by the subsequent biascorrection procedures.

The impacts of the MWTS-2 radiance data on the prediction of GRAPES are studied. Impact analysis shows that the direct assimilation of MWTS-2 observations can decrease analysis error when the control experiment uses only conventional data. After removing striping noise, the analysis error is smaller than the experiments assimilating data without correction for the striping noise; i.e., the quality control technique of removing striping noise can slightly decrease the analysis error. The impact of MWTS-2 radiance data on the GRAPES system when assimilating all data is neutral.

Analysis/forecast cycle experiments are conducted for nearly a month. When the control experiment assimilates only conventional data, the impact of MWTS-2 radiance is positive. Verifications indicate that the ACC of the $500 \mathrm{hPa}$ height forecast field slightly increase and that the RMS slightly decrease in the Northern Hemisphere. If all observations are used in the control experiment, the impact on MWTS-2 is neutral. After removing striping noise, the fore- 

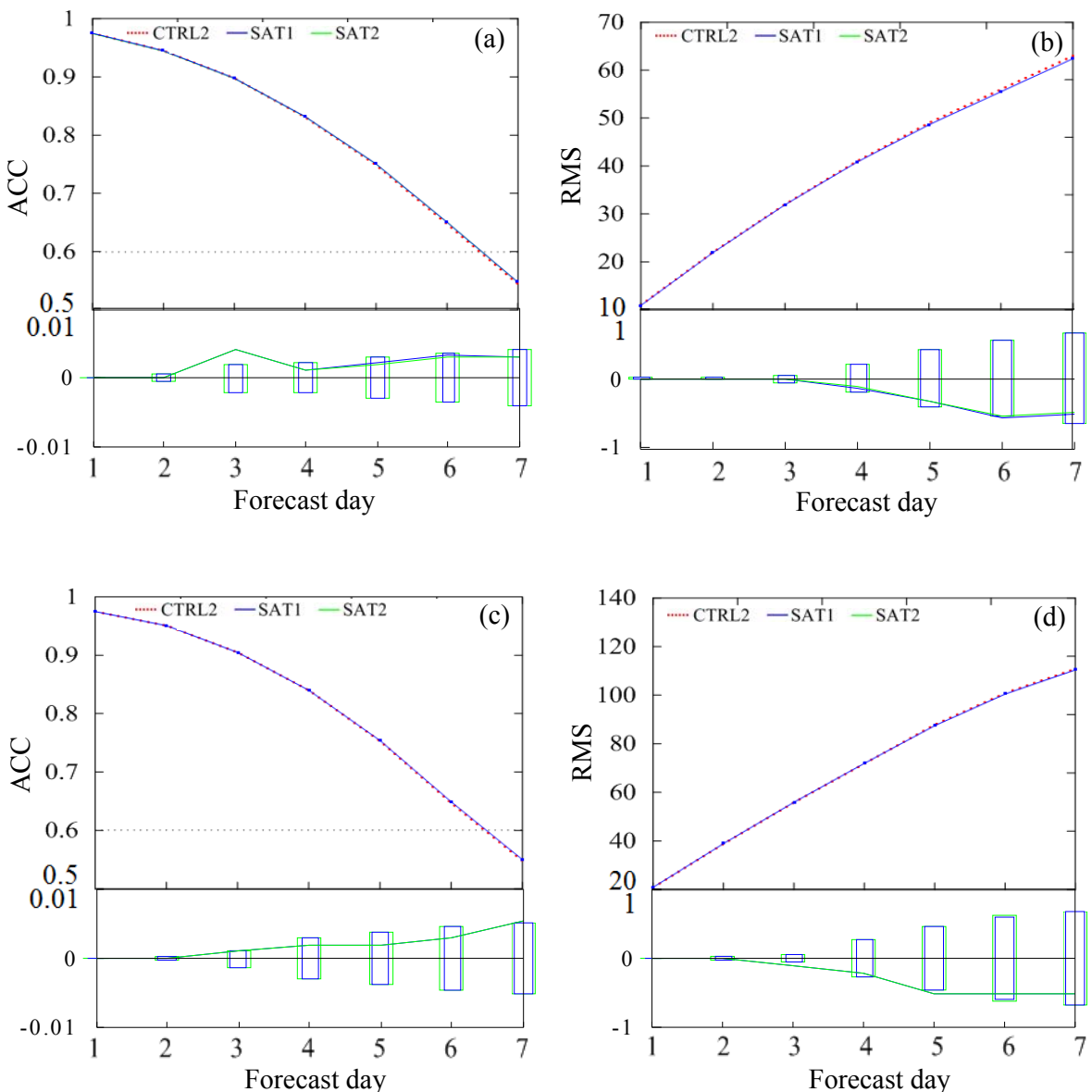

Figure 19. Mean ACC (left panels) and RMS (right panels) of $500 \mathrm{hPa}$ geopotential height of CTRL2 (red dashed line), SAT1 (blue solid line), and SAT2 (green solid line) experiments in (a-b) the Northern Hemisphere and (c-d) the Southern Hemisphere for the period from 1 to 27 July 2014. The statistical significance testing of SAT1 and CTRL2 (SAT2 and CTRL2) are shown in the lower part of each figure in blue (green). The ACC and RMS differences outside of outline bars are significant at the $95 \%$ confidence level.

cast error is smaller than the experiments assimilating data without correction for the striping noise. Overall, the assimilation of the MWTS-2 data could have a neutral to small positive impact on the assimilation and model forecast. The quality control scheme of extracting striping noise may contribute to the analysis and forecast.

The neutral MWTS-2 impact when AMSU-A is used is not surprising. After all, when a lot of similar observations (AMSU-A) have been assimilated, the impact of new data will not be so significant. In addition, in this initial study, the quality control scheme is cautions and we are conservative in choosing channels. There are three more channels used for AMSU-A than for MWTS-2. Moreover, the cloud detection method for MWTS-2 seems to have removed too much clear pixels. In consideration of these reasons, the neutral impact is in line with our expectations. After the initial evaluation of the data quality and the impact on NWP models, we are going to use more channels and try to improve the quality control scheme in the near future.
This study demonstrates the impact of the FY-3C MWTS2 observations on an NWP system. In 2016, the Chinese FY3D satellite will be launched. It carries the same instruments as those on FY-3C. The quality control scheme and impact study on FY-3C MWTS-2 will contribute to future research of FY-3D microwave sounding data.

\section{Data availability}

The $6 \mathrm{~h}$ forecasts of the vertical profiles of temperature, specific humidity and the surface pressure from the NCEP global forecast system are available at http://nomads.ncdc. noaa.gov/data/gfs-avn-hi/. 
Acknowledgements. The authors thank their colleagues for continuing support and discussion around the coffee breaks. The authors also thank the reviewers and the editor for their valuable comments and suggestions. This work was jointly supported by the China Special Fund for Meteorological Research in the Public Interest (No. GYHY201406008), Project supported by the National Natural Science Foundation of China (Grant Nos. 91337218 and 41475103).

Edited by: J. Joiner

\section{References}

Andersson, E., Pailleux, J., Thepaut, J. N., Eyre, J. R., McNally, A. P., Kelly, G. A., and Courtier, P.: Use of cloud-cleared radiances in three-four-dimensional variational data assimilation, Q. J. Roy. Meteor. Soc., 120, 627-653, doi:10.1002/qj.49712051707, 1994.

Baker, N. L. and Daley, R.: Observation and background adjoint sensitivity in the adaptive observation-targeting problem, Q. J. Roy. Meteor. Soc., 126, 1431-1454, doi:10.1002/qj.49712656511, 2000.

Cardinali, C.: Monitoring observation impact on short-range forecast, Q. J. Roy. Meteor. Soc., 135, 239-250, doi:10.1002/qj.366, 2009.

Chen, D. H., Xue, J. S., Yang, X. S., Zhang, H. L., Shen, X. S., $\mathrm{Hu}$, J. L., Wang, Y., Ji, L. R., and Chen, J. B.: New generation of multi-scale NWP system (GRAPES): general scientific design, Chin. Sci. Bull., 53, 3433-3445, doi:10.1007/s11434-008-0494z, 2008.

Courtier, P., Andersson, E., Heckley, W., Vasiljevic, D., Hamrud, M., Hollingsworth, A., Rabier, F., Fisher, M., and Pailleux, J.: The ECMWF implementation of three-dimensional variational assimilation (3D-Var). I: formulation, Q. J. Roy. Meteor. Soc., 124, 1783-1807, 1998.

Community Radiative Transfer Model (CRTM): developed by the Joint Center for Satellite Data Assimilation (JCSDA), CRTM is V2.2.3, available at: http://ftp.emc.ncep.noaa.gov/jcsda/CRTM/, October 2015.

Derber, J. C. and Wu, W. S.: The use of TOVS cloudcleared radiances in the NCEP SSI analysis system, Mon. Weather. Rev., 126, 2287-2299, doi:10.1175/15200493(1998)126<2287:TUOTCC>2.0.CO;2, 1998.

Dong, C. H., Yang, J., Yang, Z. D., Lu, N. M., Shi, J. M., Zhang, P., Liu, Y. J., Cai, B., and Zhang, W.: An overview of a new Chinese weather satellite FY-3A, Bull. Am. Meteorol. Soc., 90, 15311544, doi:10.1175/2009BAMS2798.1, 2009.

Ferraro, R. R., Weng, F. Z., Grody, N. C., Zhao, L. M., Meng, H., Kongoli, C., Pellegrino, P., Qiu, S., and Dean, C.: NOAA operational hydrological products derived from the advanced microwave sounding unit, IEEE Trans. Geosci. Rem. Sens., 43, 1036-1049, doi:10.1109/TGRS.2004.843249, 2005.

Fourrié, N., Doerenbecher, A., Bergot, T., and Joly, A.: Adjoint sensitivity of the forecast to TOVS observations, Q. J. Roy. Meteor. Soc., 128), 2759-2777, doi:10.1256/qj.01.167, 2002.

Gelaro, R., Langland, R. H., Pellerin, S., and Todling, R.: The THORPEX observation impact intercompar- ison experiment, Mon. Weather. Rev., 138, 4009-4025, doi:10.1175/2010MWR3393.1, 2010.

Grody, N., Zhao, J., Ferraro, R., Weng, F., and Boers, R.: Determination of precipitable water and cloud liquid water over oceans from the NOAA 15 advanced microwave sounding unit, J. Geophys. Res., 106, 2943-2953, 2001.

Gu, S. Y., Guo, Y., You, R. and Lu, N. M.: The performance of microwave sounders board on FY-3C satellite, Technique report, National Satellite Meteorological Center, China Meteorological Administration, Beijing, China, 2013 (in Chinese).

Guan, L., Zou, X., Weng, F., and Li, G.: Assessments of FY-3A Microwave Humidity Sounder measurements using NOAA-18 Microwave Humidity Sounder, J. Geophys. Res., 116, D10106, doi:10.1029/2010JD015412, 2011.

Guo, Y., Lu, N. M., Qi, C. L., Gu, S. Y. and Xu, J. M.: Calibration and validation of microwave humidity and temperature sounder onboard FY-3C satellite. Chinese J. Geophys., 58, 20-31, 2015 (in Chinese).

Harris, B. A. and Kelly, G.: A satellite radiance-bias correction scheme for data assimilation, Q. J. Roy. Meteor. Soc., 127, 14531468, doi:10.1002/qj.49712757418, 2001.

Klaes, D. and Schraidt, R.: The European ATOVS and AVHRR processing package (AAPP), Tech. Proc. 10th Int. ATOVS Study Conf., Boulder, USA, 1999.

Langland, R. H. and Baker, A. L.: Estimation of observation impact using the NRL atmospheric variational data assimilation adjoint system, Tellus A, 56, 189-201, doi:10.1111/j.16000870.2004.00056.x, 2004.

Lansante, J. R.: Resistant, robust and non-parametric techniques for the analysis of climate data: theory and examples, including applications to historical radiosonde station data, Int. J. Climatol., 16, 1197-1226, doi:10.1002/(SICI)10970088(199611)16:11<1197::AID-JOC89>3.0.CO;2-L, 1996.

Li, J. and Liu, G.: Assimilation of Chinese FengYun 3B 75 Microwave Temperature Sounder radiances into Global GRAPES system with an improved cloud detection threshold, Front. Earth. Sci., 10, 145-158, doi:10.1007/s11707-015-0499-2, 2015.

Li, J. and Zou, X.: A quality control procedure for FY-3A MWTS measurements with emphasis on cloud detection using VIRR cloud fraction, J. Atmos. Ocean. Technol., 30, 1704-1715, doi:10.1175/JTECH-D-12-00164.1, 2013.

Li, J. and Zou, X.: Impact of FY-3A MWTS radiances on prediction in GRAPES with comparison of two quality control schemes, Front. Earth. Sci., 8, 251-263, doi:10.1007/s11707-014-0405-3, 2014.

Lu, Q. and Bell, W.: Evaluation of FY-3B data and an assessment of passband shifts in AMSU-A and MSU during the period 19782012, Interim report of Visiting Scientist mission NWP_11_05, Document NWPSAF-EC-VS-023, Version 0.1, 28, 2012.

Lu, Q., Bell, W., Bauer, P., Bormann, N., and Peubey, C.: An initial evaluation of FY-3A satellite data, ECMWF Technical Memoranda Number 631, ECMWF, Shinfield Park, Reading, UK, 58, 2010.

Lu, Q., Lawrence, H., Bormann, N., English, S., Lean, K., Atkinson, N., Bell, W., and Carminati, F. : An evaluation of FY-3C satellite data quality at ECMWF and the Met Office, ECMWF Technical Memoranda Number 767, ECMWF, Shinfield Park, Reading, UK, 2015. 
McNally, A. P., Derber, J. C., Wu, W., and Katz, B. B.: The use of TOVS level-1b radiances in the NCEP SSI analysis system, Q. J. Roy. Meteor. Soc., 126, 689-724, doi:10.1002/qj.49712656315, 2000.

Navon, I. M. and Legler, D. M.: Conjugate gradient methods for large scale minimization in meteorology, Mon. Weather. Rev., 115, 1479-1502, doi:10.1175/15200493(1987)115<1479:CGMFLS>2.0.CO;2, 1987.

NCEP global forecast field: available at: http://nomads.ncdc.noaa. gov/data/gfs-avn-hi/, 11 July 2016.

Okamoto, K., Kazumori, M. and Owada, H.: The assimilation of ATOVS radiances in the JMA global analysis system, J. Meteor. Soc. Japan, 83, 201-217, 2005.

Parrish, D. F. and Derber, J. C.: The National Meteorological Centers spectral statistical in nterpolation analysis system, Mon. Weather. Rev., 120, 1747-1763, 1992.

Qin, Z., Zou, X., and Weng, F.: Analysis of ATMS striping noise from its Earth scene observations, J. Geophys. Res. Atmos., 118, 13214-13229, doi:10.1002/2013JD020399, 2013.

Radiative Transfer for TOVS (RTTOV): Numerical Weather Predication (NWP SAF), RTTOV V11.3, available at: http://nwpsaf. eu/site/software/rttov/downloads/\#Software, September 2015.

Saunders, R. W., Matricardi, M., and Brunel, P.: An Improved Fast Radiative Transfer Model for Assimilation of Satellite Radiance Observations, Q. J. Roy. Meteor. Soc., 125, 1407-1425, 1999.

Tobin, D. C., Revercomb, H. E., and Antonelli, P.: Principal component analysis of IASI spectra with a focus on non-uniform scene effects on the ILS, in Proc. AIP Conf, 1100, 16, AIP Publishing, Foz do Iguaçu Brazil, 2009.

van Delst, P.: CRTM: v2.0 User Guide, Joint Center for Satellite Data Assimilation, Camp Springs, Maryland, USA, 2011.
Weng, F. and Grody, N. C.: Retrieval of cloud liquid water using the special sensor microwave imager (SSM/I), J. Geophys. Res., 99, 25535-25551, doi:10.1029/94JD02304, 1994.

Wu, W. S., Purser, R. J., and Parrish, D. F.: Three-dimensional variational analysis with spatially inhomogeneous covariances, Mon. Weather. Rev., 130, 2905-2916, 2002.

Wu, Z. and Huang, N. E.: Ensemble empirical mode decomposition: A noise-assisted data analysis method, Adv. Adapt. Data Anal., $1,1-41,2009$.

Xue, J. S. and Chen, D. H.: Numerical Prediction System Design and Application of Science GRAPES, Science Press, Beijing, 383 pp., 2008 (in Chinese).

Xue, J. S., Zhuang, S. Y., Zhu, G. F., Zhang, H., Liu, Z. Q., Liu, Y., and Zhuang, Z. R.: Scientific design and preliminary results of three-dimensional variational data assimilation system of GRAPES, Chin. Sci. Bull., 53, 3446-3457, doi:10.1007/s11434008-0416-0, 2008.

Zhang, P., Yang, J., Dong, C. H., Lu, N. M., Yang, Z. D., and Shi, J. M.: General introduction on payloads, ground segment and data application of Fengyun 3A, Front. Earth. Sci., 3, 367-373, doi:10.1007/s11707-009-0036-2, 2009.

Zou, X. and Zeng, Z.: A quality control procedure for GPS radio occultation data, J. Geophys. Res., 111, D02112, doi:10.1029/2005JD005846, 2006.

Zou, X., Wang, X., Weng, F., and Guan, L.: Assessments of Chinese FengYun Microwave Temperature Sounder (MWTS) measurements for weather and climate applications, J. Atmos. Ocean. Technol., 28, 1206-1227, 2011. 